\title{
Consideraciones críticas sobre el abordaje del problema del narcotráfico en Argentina*
}

\author{
Mariana Souto Zabaleta** \\ Paula Delfino*** \\ Silvio Sebastián Sarti****
}

\begin{abstract}
RESUMEN
La ausencia de rigurosidad analitica a la hora de diseñar, implementar y evaluar politicas públicas de prevención y control del narcotráfico en Argentina es un obstáculo para diferenciar sus múltiples manifestaciones y el impacto de aquéllas. En el presente trabajo se busca analizar, a partir de la información disponible y en el marco del posicionamiento argentino en el régimen internacional de control de drogas, las transformaciones que se han producido en los últimos quince años en materia de oferta y demanda de drogas sujetas a fiscalización. Se busca advertir sobre la necesidad de contar con una comprensión del mercado ilicito de drogas y sus diferentes manifestaciones locales a la hora de diseñar e implementar politicas de prevención y control.
\end{abstract}

\section{PALABRAS CLAVE}

Régimen internacional de control de drogas, narcotráfico, políticas de prevención y control del narcotráfico, indicadores, efectividad, diagnóstico.

\begin{abstract}
The absence of analytical rigor in designing, implementing and evaluating public policies for the prevention and control of drug trafficking is an obstacle to distinguish its multiple manifestations and the impact of how the problem is dealt with in Argentina. This paper seeks to analyze, from the information available and in the framework of the Argentine position in the international drug control regime, the transformations that have occurred in the last fifteen years in terms of supply and demand of drugs that are subjected to control. It seeks to warn about the need to have an understanding of the illicit drug market and its different local manifestations when designing and implementing prevention and control policies.
\end{abstract}

\section{KEYWORDS}

International regime for drug control, drug trafficking, drug prevention and control policies, indicators, effectiveness, diagnosis.

\footnotetext{
*Artículo recibido el 28 de febrero de 2018 y aceptado para su publicación el 17 de agosto de 2018

${ }^{*}$ Coordinadora del Grupo de Estudio sobre Narcotráfico en el Instituto Latinoamericano en Seguridad y Democracia, Argentina. (mariana@soutozabaleta.com.ar) orcid.org/0000-0003-1039-6611

***Docente en la Universidad de Buenos Aires, Argentina. (pauladelfino79@gmail.com) orcid.org/0000-0002-6037-6208

****Docente en la Universidad Nacional de Tres de Febrero, Argentina. (sssarti@hotmail.com) orcid.org/0000-00033361-3391
} 


\section{SUMARIO}

1. Introducción

2. El posicionamiento argentino en el marco del régimen internacional de control de drogas: continuidades y rupturas

3. La información disponible en torno a la evolución de la oferta

4. Las transformaciones del problema del narcotráfico en los últimos 15 años

5. Una necesaria mirada a los mercados locales de consumo

6. Reflexiones finales: la complejidad del problema y la necesidad de un diagnóstico

7 Bibliografía

\section{Introducción}

El secretario general de las Naciones Unidas, en el Vigésimo Período Extraordinario de Sesiones de la Asamblea General sobre el Problema Mundial de las Drogas, celebrado en 1998, confiaba en que esos días en los que tenía lugar la sesión especial serían "el momento en el que la comunidad internacional" encontrara "puntos de acuerdo en la misión de crear un impulso para lograr un mundo libre de drogas en el siglo xxI". ${ }^{1}$ Por su parte, el director ejecutivo del Programa de Naciones Unidas para la Fiscalización Internacional de Drogas (PNUFID), Pino Arlacchi, indicaba en esa oportunidad que, con la aprobación de la Declaración Política y los Planes de Acción, se habían dado nuevos pasos para "lograr un mundo sin drogas".2

La apelación a un mundo libre de drogas se convertía así en una cuestión no sólo deseable sino también factible. Sin embargo, a medida que los resultados de la estrategia internacional de control de drogas comenzaron a resultar desalentadores, esta idea comenzó a evaporarse. La comunidad internacional debió aceptar con el correr de los años que la idea de "un mundo libre de drogas" no constituía una meta realista. Además, las estrategias implementadas no habían logrado reducir el problema en la mayoría de sus aristas y habían generado daños colaterales. ${ }^{3}$

\footnotetext{
1 Declaración del Secretario General de Naciones Unidas en su Vigésimo Periodo Extraordinario de Sesiones; A/S20/P.V.1, 1998.

2 Declaración del Director Ejecutivo del Programa de Naciones Unidas para la Fiscalización Internacional de Drogas (PNUFid), Pino Arlacchi, en el Vigésimo Período Extraordinario de Sesiones de la Asamblea General de Naciones Unidas, A/S-20/P.V.1.

${ }^{3}$ Souto Zabaleta, Mariana, Socialización, crisis de efectividad y persistencia en el régimen internacional de control de drogas, Buenos Aires, Editorial Arte \& Parte, 2017.
} 
En el caso argentino, las características de las intervenciones que ha desarrollado el Estado han presentado variaciones en el tiempo, aunque el paradigma que las ha venido sustentando parece estar en consonancia con ese horizonte de un mundo sin drogas y con el tipo de políticas que inspiraron tempranamente a la comunidad internacional. En efecto, el abordaje del problema desde los distintos ámbitos estatales (legislativo, ejecutivo, judicial) no necesariamente se ha visto acompañado de un diagnóstico riguroso acerca de su magnitud o sus diversas manifestaciones locales, ni ha contemplado una evaluación de los resultados o el impacto de las políticas implementadas. La "idea de una Argentina sin narcotráfico en un mundo libre de drogas" que ha inspirado a las políticas de prevención y control del narcotráfico resulta endeble, desde el punto de vista teórico y empírico. En efecto, se encuentra alejada de los debates en los cuales está inmersa la comunidad internacional desde hace ya varios años. ${ }^{4}$

La comunidad internacional debió reconocer no sólo la imposibilidad de alcanzar un "mundo libre de drogas” sino también la crisis de efectividad del régimen internacional de control de drogas y el importante déficit de información e incertidumbre acerca del problema. ${ }^{5}$ En el caso argentino, resulta imperioso avanzar hacia un diagnóstico preciso y certero, especialmente en lo que refiere a la caracterización del problema del narcotráfico en sus diferentes manifestaciones locales, así como hacia una evaluación de la efectividad de las estrategias de prevención y control que se implementan para enfrentarlo. Contar con ese diagnóstico y evaluar los resultados y el impacto de las políticas deviene esencial por estas horas. Como afirmara el entonces presidente uruguayo José Mujica:

De vez en cuando interceptamos una carga de droga y ganamos una batalla, de vez en cuando coordinando esfuerzos a nivel internacional damos captura a narcotraficantes y ganamos una batalla, de vez en cuando gracias al intercambio de información y la cooperación internacional detectamos y penalizamos actividades de lavado de activos y ganamos una batalla. Pero a diario, el narcotráfico recluta jóvenes de las poblaciones excluidas que terminan muertos a los veintipocos años en actos de violencia y nos damos cuenta que podremos ganar batallas, pero estamos perdiendo la guerra. ${ }^{6}$

\footnotetext{
${ }^{4}$ Ibidem.

${ }^{5}$ Ibidem.

${ }^{6}$ Intervención de Uruguay en la 43 Asamblea General de la Organización de Estados Americanos, junio de 2013.
} 
Así, en el presente trabajo se aborda el problema del narcotráfico atendiendo no sólo a sus manifestaciones visibles sino principalmente al impacto de las políticas públicas para enfrentarlo en términos de su efectividad y sus consecuencias. ${ }^{7}$ Como en otras áreas de las políticas de seguridad, las intervenciones estatales y su impacto necesariamente deben formar parte del análisis. En el caso de las políticas de prevención y control del narcotráfico, aplica con claridad lo sostenido por Baratta cuando advierte que "el sistema punitivo produce más problemas de cuantos pretende resolver". ${ }^{8}$ De acuerdo con el autor, el sistema punitivo "en lugar de componer conflictos, los reprime y, a menudo, éstos mismos adquieren un carácter más grave en su propio contexto originario; o también por efecto de la intervención penal, pueden surgir conflictos nuevos en el mismo o en otros contextos". ${ }^{9}$ Como afirma Zaffaroni, se trata de un ámbito en el que queda claro el abordaje que propone el minimalismo penal: "el poder punitivo debería limitarse a conflictos muy graves y que comprometan masivamente bienes básicos (como la vida o el medio ambiente) y resolver los conflictos de menor entidad por otras vías". ${ }^{10}$ Es aquí donde "el principio general de prevención ofrece una indicación política fundamental para una estrategia alternativa de control social. Se trata, esencialmente, de desplazar, cada vez más, el énfasis puesto en las formas de control represivo hacia formas de control preventivo". ${ }^{11}$ Como afirman Sain y Rodríguez Games refiriéndose a Latinoamérica:

Los desafíos que se imponen en nuestros países no pasan por la insulsa postulación de la necesidad de emprender una 'guerra contra las drogas', ni de llevar a cabo un combate glorioso contra el crimen organizado ni por iniciativas aisladas, sino por sentar bases institucionales necesarias para afrontar una problemática que forma parte de las sociedades capitalistas y que encuentra su impulso fundamentalmente

\footnotetext{
7 Subyace a esta perspectiva una mirada de la criminología, que es aquella que no se centra en la supuesta "desviación", sino en el poder punitivo y en los procesos de construcción social detrás de la persecución policial y penal de las actividades delictivas. Como afirma Zaffaroni, "hay muchas cosas que se nos vuelven naturales porque subjetivamente todos coincidimos o convenimos en ellas [...] con el poder punitivo pasa lo mismo: se dice que siempre existió, aunque no sea cierto [...] eso determinó que todo aquel que lo critica debe explicar por qué lo hace, en tanto que el poder punitivo no debe explicar nada acerca de su existencia". Véase BECKER, Howard, Outsiders. Hacia una sociología de la desviación, México, Siglo XXI, 2009; Berger, Peter y Luckmann, Thomas, La construcción social de la realidad, Buenos Aires, Amorrortu, 1986; Zaffaroni, Eugenio, La cuestión criminal, Buenos Aires, Planeta, 2012.

${ }^{8}$ Baratta, Alessandro, Criminología y sistema penal (Compilación in memoriam), Buenos Aires, Editorial B de F, 2004.

${ }^{9}$ Ibidem.

${ }^{10}$ Zaffaroni, Eugenio, La cuestión criminal, Buenos Aires, Planeta, 2012.

"Baratta, Alessandro, Criminología y sistema penal (Compilación in memoriam), Buenos Aires, Editorial B de F, 2004.
} 
en la demanda creciente de bienes, sustancias y servicios ilegales por parte de una porción de las distintas sociedades. ${ }^{12}$

En este abordaje, resulta necesario desprenderse del alto grado de politización y exposición mediática del problema del narcotráfico en nuestra sociedad. Curbet afirma que "las medidas adoptadas desde esta perspectiva tienden más a reaccionar, con actuaciones oportunistas, ante las expresiones atemorizadas y punitivas de la opinión pública que a responder a situaciones conflictivas que requieren tratamientos expertos, profundos y sostenidos". ${ }^{13}$

Así, resulta ineludible avanzar hacia un diagnóstico que, a su vez, incorpore una reflexión crítica respecto a la información disponible y sus límites analíticos, y se centre en el impacto efectivo de las políticas. Como señala Tokatlián, "si hay un hecho claro e incontrastable en torno a las drogas en la Argentina, es la ausencia persistente de un diagnóstico riguroso. Esto no significa que falten elementos de análisis, aunque fragmentarios y parciales, datos, información, evidencias, estadísticas, tesis, noticias, estudios e informes están disponibles y brindan un panorama de la situación existente". ${ }^{14}$

A lo largo de las páginas que siguen, intentaremos revisar la información disponible y su potencial analítico para echar luz sobre ciertas tendencias que se desprenden de ese análisis. Entendemos esto como un paso indispensable para el diseño e implementación de políticas públicas en materia de prevención y control del narcotráfico, tanto en el sentido de revisar las existentes, como de vislumbrar políticas alternativas. En este necesario análisis, aparece también como cuestión prioritaria un examen detallado de los ejes problemáticos que han recorrido y recorren el diseño y la implementación de esas políticas en Argentina en los últimos años.

Para el cumplimiento de este objetivo, se recurrirá a estadísticas oficiales y a diversas investigaciones empíricas que, en su mayoría, utilizan un andamiaje metodológico cuali-cuantitativo. ${ }^{15}$ Respecto de las estadísticas oficiales y en

\footnotetext{
12 Sain, Marcelo y Rodriguez Games, Nicolás, Tendencias y Desafíos del Crimen Organizado en Latinoamérica, Buenos Aires, UMET, 2015.

${ }^{13}$ Cunbet, Jaume, El rey desnudo: la gobernabilidad de la seguridad ciudadana, Barcelona, voc, 2009.

${ }^{14}$ ToKatLIÁN, JuAN, ¿Qué hacer con las drogas? Una mirada progresista sobre un tema habitualmente abordado desde el oportunismo político y los intereses creados, Buenos Aires, Siglo XXI, 2017.

${ }^{15}$ En términos de Marradi, este tipo de andamiajes metodológicos se enclavan en la idea de que "la cuestión de los métodos cuantitativos y cualitativos" no se resuelve "en el plano de las discusiones filosóficas sobre la realidad, sino en el plano de la racionalidad de medios afines entre un problema cognitivo de interés, un diseño de investigación apropiado al problema y los instrumentos técnicos más adecuados para resolverlo". De acuerdo con el autor, "ambos métodos no son incompatibles, hecho del que deriva la posibilidad de integración siempre que esto repercuta en un mejor abordaje del problema en cuestión". Marradi, Alberto, Archenti, Néllda, y Piovani, Juan, Metodología de las
} 
línea con el abordaje criminológico planteado precedentemente, es preciso señalar que ellas no expresan necesariamente la criminalidad real sino más bien aquellos comportamientos que son objeto de la persecución policial y penal. En términos de Sozzo, resulta necesario advertir la diferencia entre la "criminalidad real" y la "criminalidad aparente" y tener en cuenta la importancia de las estadísticas oficiales "para acercarnos a la cuestión compleja del conocimiento del delito", que principalmente arrojan luz respecto del funcionamiento del sistema policial y penal frente a él. ${ }^{16}$

En el presente trabajo se busca, a partir de la información disponible, analizar las transformaciones que se han producido en los últimos quince años en materia de oferta y demanda de drogas sujetas a fiscalización. Asimismo, intentamos establecer ejes problemáticos en las políticas de prevención y control del narcotráfico que se vienen implementando. El objetivo del trabajo es advertir sobre la necesidad de comprender el mercado ilícito de drogas y sus diferentes manifestaciones locales a la hora de diseñar políticas de control. Se trata de abrir el camino a políticas más orientadas a la prevención por encima del foco tradicional en lo punitivo.

\section{El posicionamiento argentino en el marco del régimen internacional de control de drogas: continuidades y rupturas}

Argentina, desde la década de los noventa, ha sido un actor muy activo en su participación en el régimen internacional de control de drogas. Sus pilares son las tres convenciones de fiscalización internacional de drogas (1961, 1971 y 1988). El diseño e implementación de políticas públicas en el área se mostró ajustado a los lineamientos del régimen internacional en su expresión más tradicional, con un fuerte sesgo en su dimensión punitiva. Un claro cambio en la retórica frente al problema tuvo lugar hacia el año 2008 con la creación, en el ámbito de la

Ciencias Sociales, Buenos Aires, Emecé, 2007. Más allá de los cuestionamientos existentes en la literatura, "la mayoria de los investigadores ha optado por posiciones más pragmáticas; incluso admitiendo que las distintas formas de investigación conllevan compromisos epistemológicos". Briman, Alan, Social research methods, Oxford, Oxford University Press, 2004.

${ }^{16}$ Sozzo, Máxımo, ¿Contando el delito? Análisis crítico y comparativo de las encuestas de victimización en Argentina, Argentina, Universidad Del Litoral, 2000. 
Jefatura de Gabinete de Ministros, de un comité de reconocidos expertos, ${ }^{17}$ con el Fallo Arriola ${ }^{18}$ en 2009 y la Ley de Salud Mental ${ }^{19}$ en 2010.

Estas transformaciones a nivel doméstico comenzaron a derramarse en la participación en el régimen internacional de control de drogas, aunque con curiosas contradicciones en los foros multilaterales más relevantes, en función de la representación de la administración pública nacional con competencia en la materia. El cambio perceptible en el nivel discursivo y la participación de Argentina en las instancias multilaterales del régimen tendrá lugar recién en el año 2012, a tono con el clima de debate y reflexión que irrumpe en la región a partir del Mandato de Cartagena. A partir del año 2016, sin embargo, la nueva administración retomó una retórica más conservadora y una participación más cercana al modelo tradicional de abordaje propio de la década de los noventa. Cabe advertir que las transformaciones verificadas en el plano retórico no impactaron de manera efectiva en un cambio de políticas a nivel doméstico, como lo prueba el hecho de que el régimen penal de estupefacientes permanece inalterado desde el año 1989.

En efecto, en lo que refiere al ámbito nacional, las políticas frente al problema de las drogas han recorrido un camino ajustado a los lineamientos del régimen internacional en su expresión más tradicional. Al igual que lo sucedido en ese ámbito, el abordaje del problema de las drogas en Argentina se ha caracterizado por un mayor énfasis en los aspectos represivos que en aquellos vinculados a una aproximación desde la salud pública. Esto se verifica tanto en la relevancia política otorgada a cada área como, principalmente, en los presupuestos destinados a una y otra esfera de políticas públicas. Mientras tanto, el problema del narcotráfico, en particular, se ha convertido en uno de los temas

\footnotetext{
${ }^{17}$ El Comité Científico Asesor en Materia del Control de Tráfico llícito de Estupefacientes, dependiente de la Jefatura de Gabinete, presidido por la fiscal Mónica Cuñarro, estaba integrado por los jueces Martín Vázquez Acuña, Roberto Falcone y Patricia Llerena; el camarista Horacio Catani; el sociólogo Alberto Calabrese; la psicoanalista Eva Giberti, y los especialistas Carlos Damín, Alicia Gillone y Mónica Nápoli.

${ }^{18}$ El "Fallo Arriola" declara la inconstitucionalidad del artículo 14, segundo párrafo, de la ley 23.737. En opinión de la Csjn, "el artículo14, segundo párrafo, de la ley 23.737 debe ser invalidado, pues conculca el artículo 19 de la Constitución Nacional, en la medida en que invade la esfera de la libertad personal excluida de la autoridad de los órganos estatales". Por tal motivo, "declara la inconstitucionalidad de esa disposición legal en cuanto incrimina la tenencia de estupefacientes para uso personal que se realice en condiciones tales que no traigan aparejado un peligro concreto o un daño a derechos o bienes de terceros". Como la misma csın advierte en el fallo, "se hace uso de la reserva convencional internacional descartando la criminalización del consumidor" mientras que "la conducta no punible solo es aquella que se da en especificas circunstancias que no causan daños a un tercero".

${ }^{19}$ De acuerdo con la Ley 26.657, "las adicciones deben ser abordadas como parte integrante de las políticas de salud mental. Las personas con uso problemático de drogas, legales e ilegales, tienen todos los derechos y garantías que se establecen en la presente ley en su relación con los servicios de salud".
} 
de agenda prioritarios en la gestión de la seguridad pública en Argentina en las últimas décadas.

Frente a la existencia de un problema tal, es importante reconocer, en términos de Garland, que para los actores políticos se trata tanto de una cuestión de retórica como de efectividad práctica: "las decisiones políticas están fuertemente determinadas por la necesidad de encontrar medidas efectivas y populares que no sean visualizadas por el público como signos de debilidad o como un abandono de las responsabilidades estatales", dado que "las medidas con las cuales se identifican los funcionarios electos deben ser penológicamente creíbles pero, sobre todo, deben gozar de credibilidad política y apoyo popular". ${ }^{20}$

En tanto tema central de la agenda de la seguridad pública, la tentación a la mera retórica por encima de las acciones concretas está siempre presente. Lo cierto es que, más allá de la retórica, es posible encontrar más continuidades que cambios en las últimas administraciones de gobierno, desde que los rasgos del tradicional abordaje del problema se encuentran fuertemente condicionados, como hemos planteado, por los lineamientos del régimen de control de drogas vigente a nivel internacional, ${ }^{21}$ por un lado, y por las características de la gestión de la seguridad pública en Argentina en general, por el otro.

\section{La información disponible en torno a la evolución de la oferta}

Frente a la necesidad de analizar el problema del narcotráfico, en Argentina, como en muchos otros países, suele recurrirse a la información sobre la evolución de las incautaciones de estupefacientes como indicador prioritario. Si bien se trata de uno de los indicadores más utilizados, su capacidad analítica es limitada. En su informe sobre la situación mundial del tráfico ilícito de drogas, publicado en el año 2001, ${ }^{22}$ el director ejecutivo de la Oficina de Naciones Unidas contra la Droga y el Delito advertía que "pese a ser el indicador más importante utilizado, las incautaciones no son un indicador directo sino indirecto, desde que reflejan tanto la amplitud y eficacia de la capacidad de represión antidroga de cada país como las tendencias del tráfico".

Pese a ello, se trata de la información usualmente disponible cuando se analiza el problema de la comercialización ilícita de drogas. Su utilización más amplia se verifica en el ámbito de la política en el que suele presentarse este tipo

\footnotetext{
${ }^{20}$ GaRLAND, DAVId, La cultura del control. Crimen y orden social en la sociedad contemporánea, Madrid, Gedisa, 2001. ${ }^{21}$ Sozzo, Máxımo, ¿Contando el delito? Análisis crítico y comparativo de las encuestas de victimización en Argentina, Argentina, Universidad Del Litoral, 2000.

${ }^{22}$ ONUDD, Informe del Director Ejecutivo, E/CN.7/2001/5.
} 
de información con un tinte claramente exitista. En efecto, es posible recorrer a lo largo del tiempo reiteradas expresiones públicas de altos funcionarios vinculados con el problema del narcotráfico, marcando la supuesta eficacia de su accionar en términos de la cantidad de estupefacientes incautados. ${ }^{23}$ No obstante, como afirman Reuter y Trautmann los datos sobre incautaciones no son un indicador del tráfico, pues sólo un limitado porcentaje de las drogas que se trafican son incautadas. ${ }^{24}$

En una línea similar, Kilmer y Hoorens, citando a Reuter, plantean que las cantidades de droga incautada están condicionadas, al menos, a tres factores: la cantidad traficada, la relativa habilidad de los interdictores y el cuidado tomado por los traficantes. ${ }^{25}$ Ya a principios de los noventa Caulkins advertía que las incautaciones no se determinan sólo por el volumen de las drogas traficadas sino que también dependían del nivel de aplicación de la ley, la efectividad con las que los recursos son aplicados y las habilidades de evasión de los traficantes. De acuerdo con el autor, ninguno de estos factores se mantiene constante en el tiempo y, al menos los últimos dos, son difíciles de cuantificar. ${ }^{26}$ Por ello, la información sobre incautaciones, detenciones y encarcelamientos necesariamente debe analizarse junto con otros indicadores, principalmente los mercados de consumo. En suma, la correcta lectura del indicador 'incautaciones' no sólo demuestra un crecimiento sostenido del problema del tráfico ilícito de drogas a lo largo del tiempo, sino que, al complementarse con otros datos, coadyuva a describir la complejidad del mercado ilícito de las drogas en Argentina.

De acuerdo con la información suministrada por Argentina a Naciones Unidas en el período 1980-2015, ${ }^{27}$ las cantidades de cocaína (base, sales y crack) incautadas muestran un importante crecimiento a lo largo de los años, con una reducción significativa en el año 2015. Si bien Naciones Unidas no ha publicado aún la información correspondiente al año 2016, los datos que se manejan localmente muestran un nuevo crecimiento de las incautaciones en ese año. En función de la información disponible, es posible observar crecimientos sostenidos en el período 1990-1997, así como en el período 2003-2009.

\footnotetext{
${ }^{23}$ Tanto la actual gestión como la anterior identifican una mayor cantidad de incautaciones -que, como veremos, fueron casi siempre en cantidades crecientes en los últimos años- con mayores niveles de operatividad del estado. ${ }^{24}$ Reuter, Peter y Trautmann, Franz, A report on global illicit drug markets 1998-2007, European Commission, 2009.

${ }^{25}$ KILMER, BeAu Y Hoorens, StIJn, Understanding illicit drug markets, supply reduction efforts and drug related crime in the European Union, Comisión Europea, 2010.

${ }^{26}$ CAULKInS, Jonathan, The distribution and consumption of illicit drugs: some mathematical models and their policy implications, MIT, 1990.

${ }^{27}$ Cabe advertir que Argentina envió información parcial (sólo la suministrada por las fuerzas policiales provinciales) en los años 2010 y 2011, por lo que no se consignan datos para esos años.
} 
Particularmente a partir del año 2005, las cantidades de incautaciones de cocaína en todas sus formas comienzan más que a duplicar el más alto valor histórico registrado en el año 1997.

Esa tendencia se registra hasta el año 2014 en que comienzan a declinar y ya de un modo más abrupto en el año 2015, cuando las cantidades incautadas vuelven a valores similares al año 2006. No obstante, una nueva tendencia creciente vuelve a aparecer en el año 2016 (8431.39 kilos). Desde 2005 hasta 2015, la cantidad de cocaína incautada no ha sido menor a las 6 toneladas anuales con un récord histórico de más de 12 toneladas en el año 2009 (véase gráfico 1). En esta evolución queda clara la tendencia creciente desde la década de los noventa y un ritmo ascendente más marcado en el inicio del nuevo milenio.
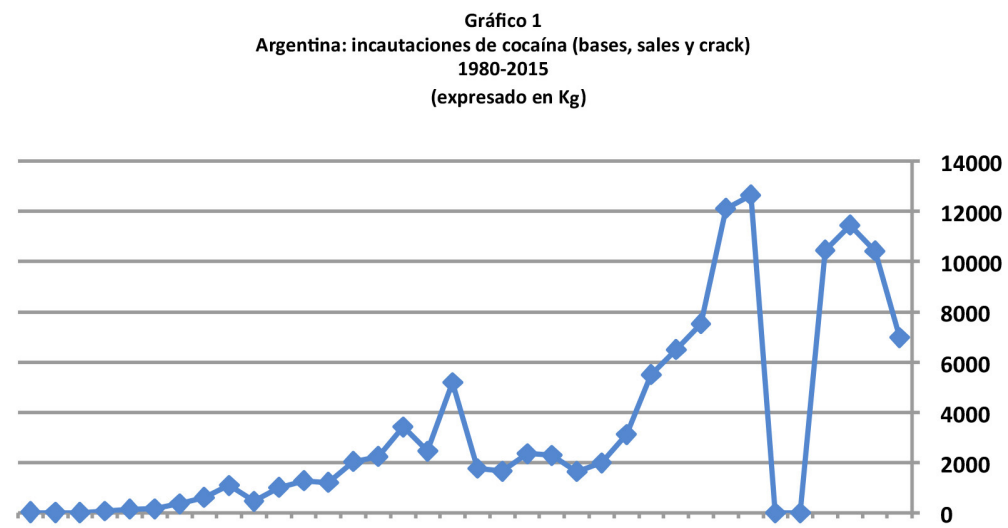

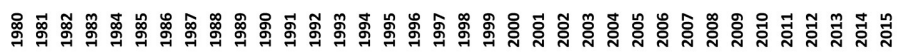

Fuente: elaboración propia con base en Drug Seizures Report, Argentina, UNODC Statistics Online. Disponible en: https:// data.unodc.org

Esta tendencia creciente en materia de incautaciones de cocaína se verifica en todos los países del Cono Sur, más específicamente en el período 2000-2013 (véase gráfico 2). ${ }^{28}$ En términos de las cantidades incautadas, es relevante el papel de Brasil cuyo máximo valor histórico supera las 40 toneladas anuales en el año 2013; asimismo, es considerable el incremento que se verifica a partir de 2006 y, fundamentalmente, a partir del año 2012. Asimismo, a partir del año 2013 todos los países muestran disminuciones -o al menos una

\footnotetext{
${ }^{28}$ Elaboración propia con base en la información disponible en Drug Seizures Report, Argentina, unodc Statistics Online. Disponible en: https://data.unodc.org
} 

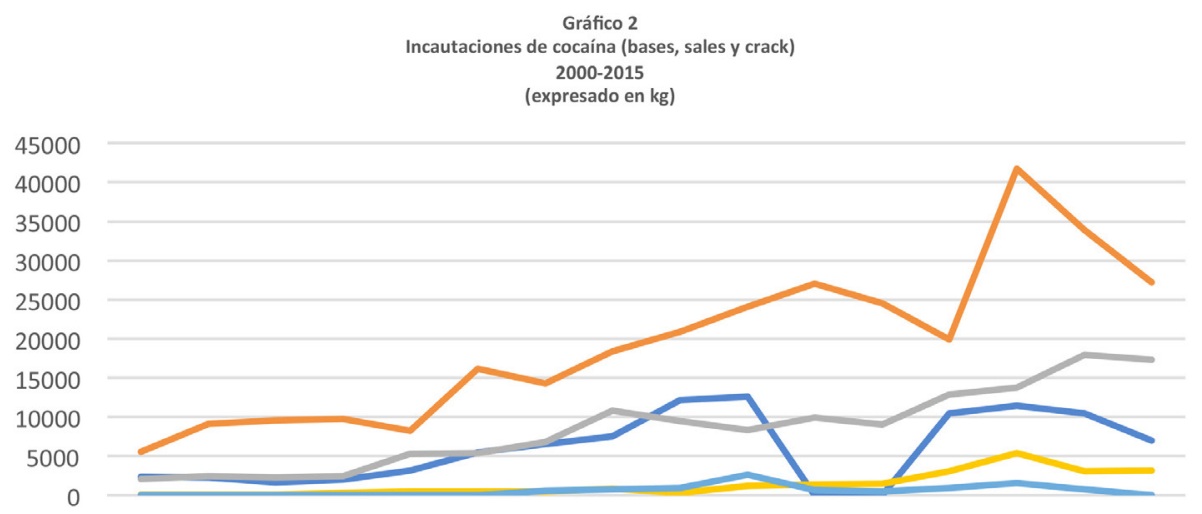

2000200120022003200420052006200720082009201020112012201320142015

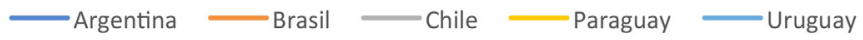

estabilización- en las cantidades incautadas. Esta información comparada parece hablar más del crecimiento de los mercados locales de consumo en la región que de la eficacia policial.

Si bien es cierto que las incautaciones en general muestran un crecimiento a nivel internacional y regional, particularmente a partir de la aprobación en el año 1988 de la Convención de Naciones Unidas contra el Tráfico Ilícito de Drogas y de la Declaración Política y los Planes de Acción en el año 1998, la situación relativa de nuestro país en materia de incautaciones de cocaína (bases, sales y crack) también debe tomarse en cuenta. En la clasificación anual de los principales países donde se incautó cocaína de la Oficina de Naciones Unidas contra la Droga y el Delito (onUdD), en sus sucesivos Informes Mundiales sobre Drogas, Argentina pasó de ocupar el lugar 21, en el año 2001, al 18 en el año 2015 (véase gráfico 3). ${ }^{29}$ En términos simples, en el año 2001 otros veinte países incautaban más cocaína que nuestro país; en el 2013, 17. Para dimensionar el listado de la onUDD, es importante destacar que Argentina, en el año 2015, fue responsable de tan sólo 0.8\% de las incautaciones mundiales de cocaína; los principales países en el listado fueron Colombia (34\%), Estados Unidos (15\%), Ecuador (8\%), Venezuela (8\%) y Panamá (6\%). Aún en aquellos años en los que Argentina aparece en una posición más destacada (12), las cantidades incautadas no implicaron más que $2 \%$ del total mundial de incautaciones de cocaína.

\footnotetext{
${ }^{29}$ Elaboración propia con base en la información disponible en los Informes Mundiales sobre Drogas elaborado por la ONUDD.
} 


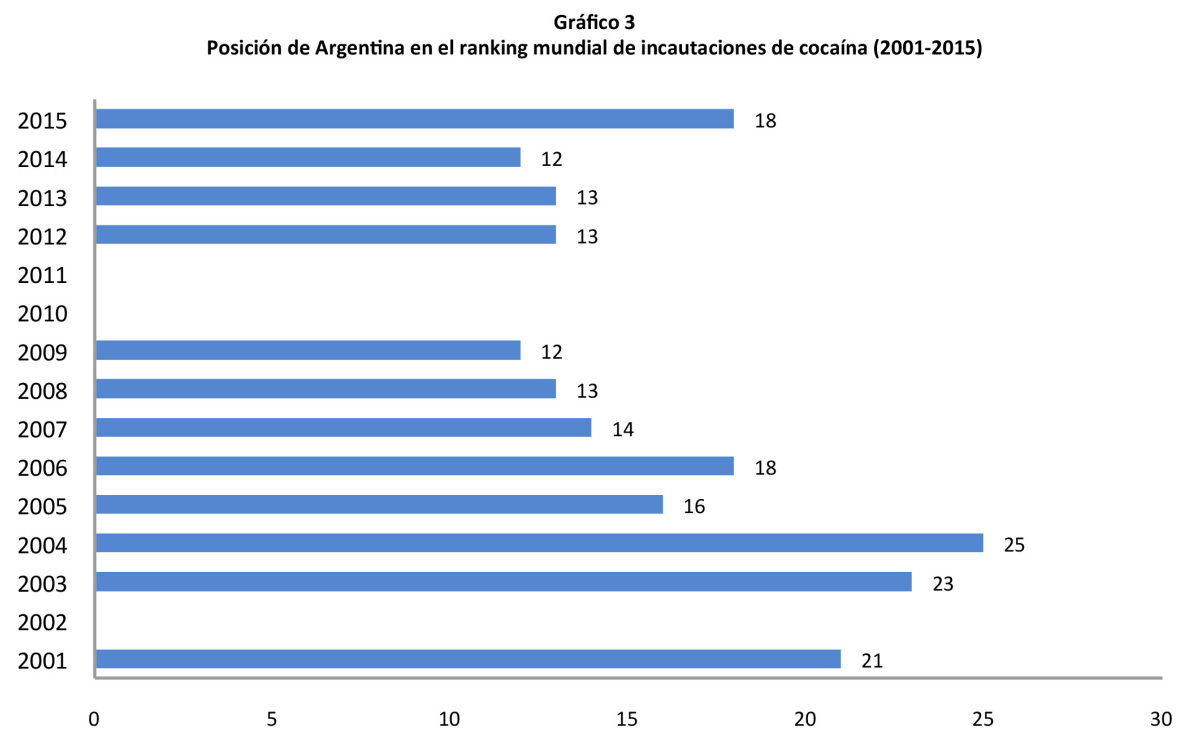

En el caso de las incautaciones de cannabis, la primera tendencia de crecimiento sostenido se verifica en el período 1995-2004, con una segunda tendencia ya mucho más marcada al alza entre 2006-2015, otra vez, más que duplicando los más altos niveles históricos (véase gráfico 4). ${ }^{30}$ Desde el año 2012, es notable el crecimiento de las cantidades incautadas, que alcanzó en 2015 las 200 toneladas anuales. Si bien Naciones Unidas no ha publicado información correspondiente a 2016, la información local indica una disminución en 2016 (160 553.42 kilos). Algunos medios de prensa indican que el año 2017 podría constituirse en "otro año récord" en materia de incautaciones de cannabis. Esta tendencia se verifica en todos los países del Cono Sur en el período 1998-2013 (véase gráfico 5). ${ }^{31} \mathrm{En}$ este caso, en términos de magnitudes se destacan Paraguay y Brasil, mientras que Argentina ocupa un nivel intermedio frente a los muy menores niveles de incautaciones que presentan Chile y Uruguay, aunque para todos ellos, una vez más, la tendencia en el período 1998-2015 es creciente.

\footnotetext{
${ }^{30}$ Elaboración propia en base a la información disponible en Drug Seizures Report, Argentina, unodc Statistics Online. Disponible en: https://data.unodc.org

${ }^{31}$ Elaboración propia con base en la información disponible en Drug Seizures Report, unodc Statistics Online. Disponible en: https://data.unodc.org
} 


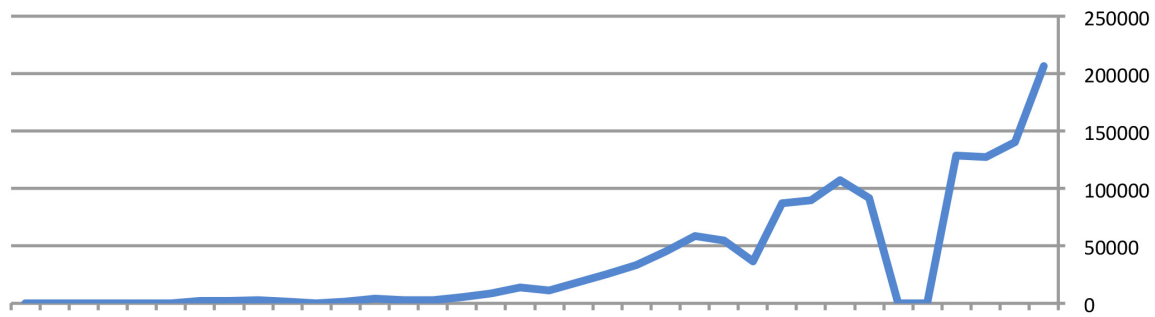

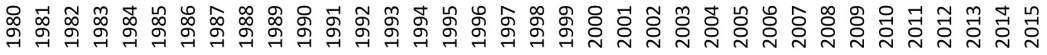

Gráfico 5

Incautaciones de marihuana (1998-2015)

(expresado en $\mathrm{kg}$ )

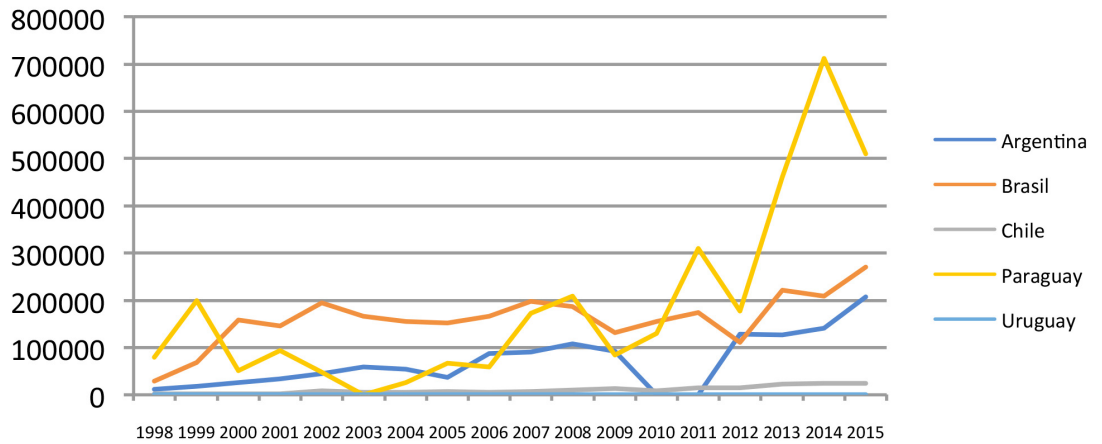

El posicionamiento relativo de Argentina en el índice mundial elaborado por Naciones Unidas, en lo que se refiere a incautaciones de cannabis, una vez más, muestra variaciones importantes a lo largo del tiempo (véase gráfico 6). ${ }^{32} \mathrm{Ar}$ gentina pasa así de ocupar el lugar 16 en el año 2001 a ocupar el lugar 9 el año 2015, luego de haber ocupado la posición 7 en el año 2012. En 2015, último año analizado, sólo ocho países habían incautado mayores cantidades de cannabis que nuestro país, aunque Argentina había sido responsable sólo de 4\% de las cantidades incautadas a nivel internacional. La preceden en el índice para ese año México (21\%), Estados Unidos (17\%), Nigeria (15\%), Paraguay (9\%), Egipto (6\%), Marruecos (5\%), Brasil (5\%) y Colombia (4\%).

\footnotetext{
32 Elaboración propia con base en la información disponible en los Informes Mundiales sobre Drogas elaborado por la ONUDD.
} 


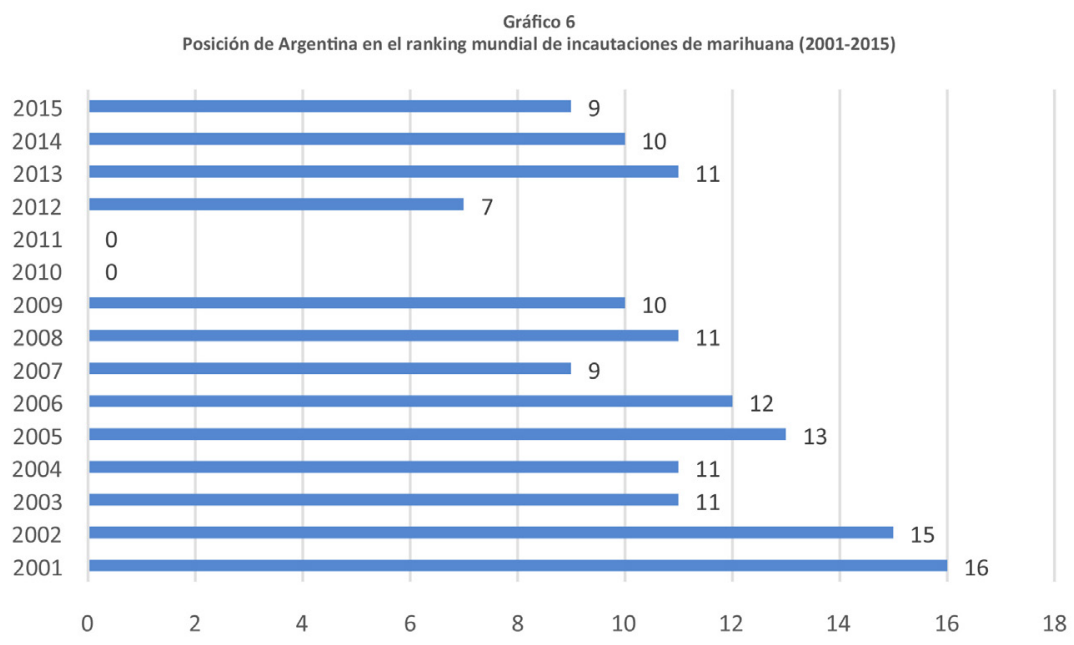

Se dio una tendencia creciente en materia de incautaciones respecto a los estimulantes de tipo anfetamínico (ETA), rótulo bajo el cual se incluyen anfetaminas, sustancias tipo éxtasis y metanfetaminas. En términos generales, suelen presentarse dificultades en la identificación precisa de la composición química de estas sustancias, por lo que muchas veces se incluye en este agregado a todas aquellas que, aunque pertenecen al grupo de ETA, no cuentan con una especificación precisa. Las cantidades incautadas de este tipo de sustancias presentan grandes variaciones en el período 1980-2015; no obstante, es posible advertir un crecimiento destacado a partir del año 2004, que supera ampliamente el más alto valor histórico que se había verificado en el año 1985, incluso hasta triplicarlo y con un salto significativo en el año 2014 (véase gráfico 7). ${ }^{33}$ Es importante destacar que la mayor parte de las incautaciones de ETA en Argentina refieren a sustancias tipo éxtasis; hay menores cantidades incautadas de anfetaminas y escasas de metanfetaminas en el período (véase gráfico 8).$^{34}$ Los valores que circulan localmente respecto al año 2016 indicarían una disminución importante en las cantidades incautadas tanto a lo que refiere a ETA en general, como al éxtasis en particular, respecto del año anterior, aunque en similares valores a los de los años anteriores de la década.

\footnotetext{
${ }^{33}$ Elaboración propia con base en la información disponible en Drug Seizures Report, Argentina, unodc Statistics Online. Disponible en: https://data.unodc.org

${ }^{34}$ Elaboración propia en base a la información disponible en Drug Seizures Report, Argentina, unodc Statistics Online. Disponible en: https://data.unodc.org
} 


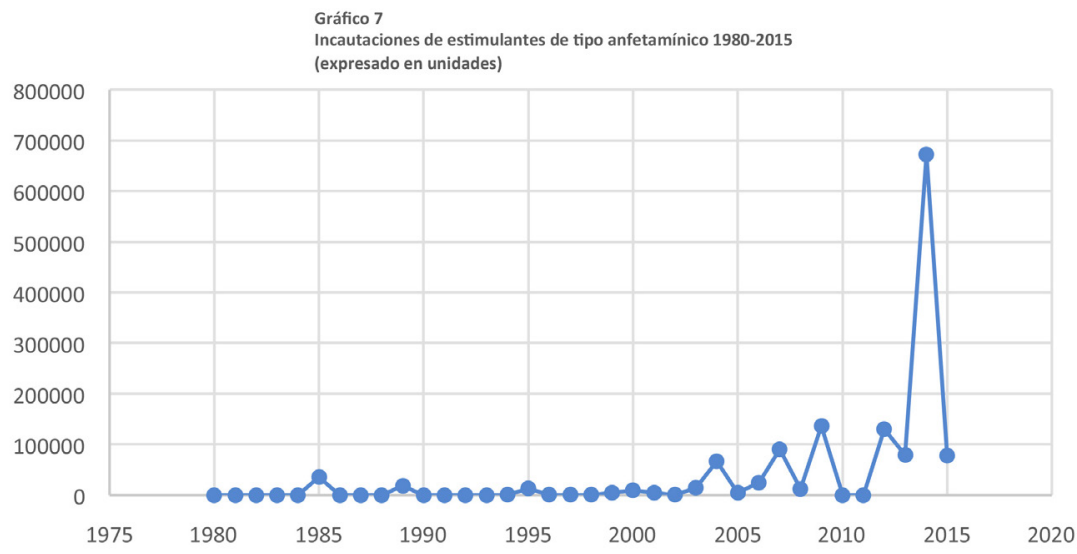

Gráfico 8
Incautaciones de estimulantes de tipo anfetamínico

1980-2015

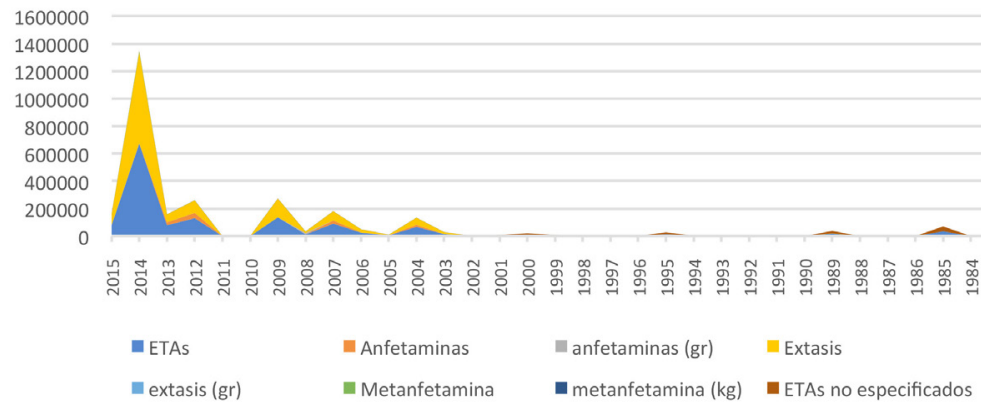

A diferencia de lo que ocurre en el caso de las incautaciones de cocaína y de cannabis, Argentina no ha ocupado posiciones en los índices de incautaciones mundiales elaborados por Naciones Unidas en el período 2001-2015 en lo que refiere a ETA, excluido el éxtasis. Respecto a esta última sustancia, nuestro país comienza a aparecer en el índice del año 2009 en la posición 11 (0.7\% de las incautaciones mundiales) y continúa esta misma tendencia en los años 2010 (posición 15, 0.3\% de las incautaciones mundiales), 2012 (posición 16, 0.5\% de las incautaciones mundiales), 2013 (posición 20, 0.4\% de las incautaciones mundiales), 2014 (posición 10, 2\% de las incautaciones mundiales) y 2015 (posición 22, 0.4\% de las incautaciones mundiales). ${ }^{35}$

\footnotetext{
${ }^{35}$ Informes Mundiales sobre Drogas 2003-2013, Oficina de Naciones Unidas contra la Droga y el Delito (onUdD).
} 
Otra de las sustancias sistemáticamente incautadas en el período 19802015 es el LSD, aunque con muchas variaciones a lo largo del tiempo, con máximos históricos de aproximadamente 50000 dosis en 1993 y en 1995, cerca de 88000 en el año 2012 y 150000 en el año 2015. En el resto de los años que comprenden el período no se verificaron incautaciones mayores a las 15000 dosis anuales (véase gráfico 8) ${ }^{36}$ En el caso de la heroína, las incautaciones se verifican principalmente en el período 1997-2006, con un máximo histórico de 175 kilos en el año 2003. No obstante, las incautaciones anuales de este lapso no son significativas. ${ }^{37}$
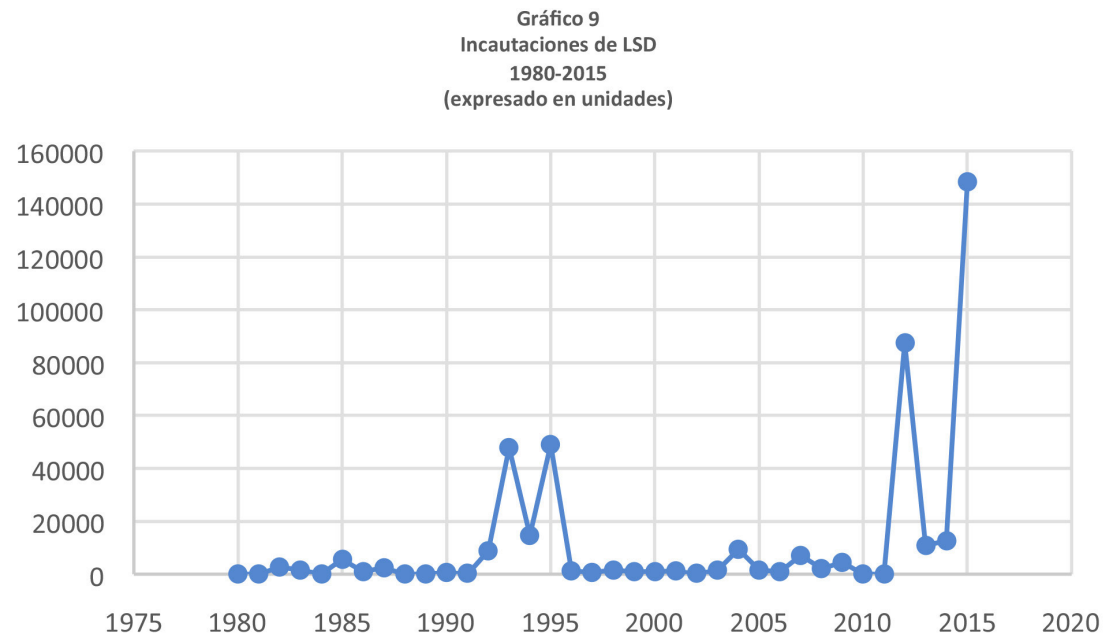

$\mathrm{Al}$ analizar las cantidades de estupefacientes incautadas a lo largo de los años, se verifica una tendencia al crecimiento sostenido a nivel nacional y regional. Lo que se desprende de esta tendencia (derivada de un análisis de la evolución de las incautaciones) sólo es comprensible si se analiza además la evolución de los indicadores de la magnitud del consumo a lo largo de esos años y, especialmente, si se trabaja en un entendimiento más profundo de las transformaciones por las que ha atravesado el problema de narcotráfico a nivel nacional en los últimos quince años.

\footnotetext{
${ }^{36}$ Elaboración propia con base en la información disponible en Drug Seizures Report, Argentina, unodc Statistics Online. Disponible en: https://data.unodc.org

${ }^{37}$ Informes Mundiales sobre Drogas 2003-2013, Oficina de Naciones Unidas contra la Droga y el Delito (onUdD).
} 


\section{Las transformaciones del problema del narcotráfico en los últimos 15 años}

Si bien las caracterizaciones de los países en términos de "productores, de tránsito o de consumo" han sido desde hace tiempo cuestionadas por la comunidad internacional, Argentina ha sido históricamente identificada en el concierto de las naciones como un país de tránsito de cocaína, principalmente hacia los mercados europeos. De igual manera, ha sido considerado como uno de los principales países potencialmente proveedores de sustancias químicas utilizables en la fabricación ilícita de drogas. En efecto, en los informes anuales (International Narcotic Control Strategy Reports) que elabora el Departamento de Estado de los Estados Unidos, ${ }^{38}$ Argentina nunca fue calificada como uno de los principales países productores o de tránsito, sino como uno de los "principales países proveedores de precursores químicos" susceptibles de ser utilizados en la fabricación ilícita de drogas. Adicionalmente, fue incluido en el grupo de "principales países de lavado de dinero" en los informes publicados en los años 1996, 2013, 2014 y 2015. ${ }^{39}$

No obstante, más allá de esta caracterización foránea, lo cierto es que el problema del narcotráfico en Argentina ha atravesado en los últimos quince años una serie de transformaciones que se produjeron en dos etapas diferenciadas. De ahí que la verdadera complejidad de problema radica entonces no sólo en el crecimiento de las cantidades incautadas a lo largo de los años, sino, principalmente, en las transformaciones que se produjeron en el país con relación a los mercados locales de consumo. En una primera etapa, que comienza con el nuevo milenio, se agregó al tradicional circuito de tránsito de clorhidrato de cocaína andina (cuyo destino final es el mercado europeo) una nueva dinámica asociada con el crecimiento de los mercados locales de consumo, particularmente en los grandes centros urbanos del país.

Esta tendencia creciente de los mercados locales de consumo es coincidente con un mercado ilícito de estupefacientes regional e internacional en expansión, y no puede dejar de asociarse con factores más profundos, relacionados con los modelos de desarrollo de las actuales sociedades. Esta transformación obliga a diferenciar entonces dos manifestaciones del problema del narcotráfico en el territorio nacional: un macrotráfico (característico del tradicional circuito de tránsito hacia mercados foráneos) y un microtráfico (vinculado con

\footnotetext{
38

${ }^{39}$ International Drug Control Strategy Report 1996-2016, US State Department.
} 
el crecimiento de los mercados locales de consumo). ${ }^{40}$ Como sostienen Lasa ${ }^{41}$ y Sain, ${ }^{42}$ en Argentina, durante la última década y media, el narcotráfico se ha transformado en dos sentidos. Por un lado, se produjo la emergencia y expansión de mercados internos de drogas ilegales (en particular, de cocaína) en las grandes urbes del país. Por otro lado, se expandió y diversificó el tráfico internacional de cocaína y otras sustancias prohibidas hacia mercados de alto consumo, en particular al europeo.

La diferenciación entre estas dos manifestaciones no es un ejercicio meramente teórico. Existen diferencias en torno a las características de las sustancias objeto de comercialización ilícita, así como de las redes/organizaciones dedicadas a ella, incluso en términos de modalidades delictivas, entre las manifestaciones macro y micro del problema. Dos mundos esencialmente diferentes emergen cuando, a partir de la información empírica, se evidencia la existencia de dos tipos de tráfico: microtráfico y macrotráfico. Cada una de estas manifestaciones presenta características distintivas en términos de las redes $u$ organizaciones involucradas, el tipo de sustancias y las cantidades en juego, los mecanismos y modalidades utilizados para su transporte, acondicionamiento y comercialización. Una vez que se produce el ingreso de estupefacientes al territorio nacional, es necesario establecer con claridad la diferenciación entre el tráfico ilícito orientado al abastecimiento del mercado local de aquel destinado al exterior. ${ }^{43}$

Con el correr de los años, no obstante, es posible establecer una segunda etapa en la evolución del problema del narcotráfico. El crecimiento del circuito de tránsito, así como del orientado al abastecimiento de los mercados locales, incorpora una mayor complejidad en la operatoria de las redes $\mathrm{u}$ organizaciones criminales dedicadas a la comercialización ilícita de drogas. En el caso del macrotráfico, aparece una más delicada división del trabajo, con la formación de redes de colaboración segmentada, mayor capacidad de control del circuito

\footnotetext{
${ }^{40}$ Se evita caracterizar a esta manifestación con el término "narcomenudeo" no sólo en miras a evitar las distorsiones que genera el uso irreflexivo del prefijo narco-, sino también porque los esquemas de microtráfico no pueden reducirse a la mera "venta minorista". Más bien entrañan una dinámica propia que excede el momento de comercialización al consumidor.

${ }^{41}$ LASA, M. "Narco made in Argentina". En Bastión Digital, Buenos Aires, 2015

${ }^{42}$ SalN, Marcelo, "Entre mitos y fabulaciones políticas: el control del narcotráfico en Argentina (2003-2017)", Ponencia presentada en el XXXVI International Congress of the Latin American Studies Association, Barcelona, 23-26 de mayo, 2018.

${ }^{43}$ Provincia de Salta, Secretaría de Programación para la Prevención de la Drogadicción y la Lucha contra el Narcotráfico y Agencia Antidrogas. Primer Estudio de Diagnóstico sobre Narcotráfico en la Provincia de Salta, Octubre de 2011. Disponible en: http://www.soutozabaleta.com.ar/index.php/primer-estudio-de-diagnostico-sobre-narcotrafico-en-la-provincia-de-saltal
} 
de comercialización, de innovación y de cooptación de colaboradores locales. En el caso del microtráfico, se dio la aparición de organizaciones locales más complejas, con dominio territorial y mayores índices de violencia.

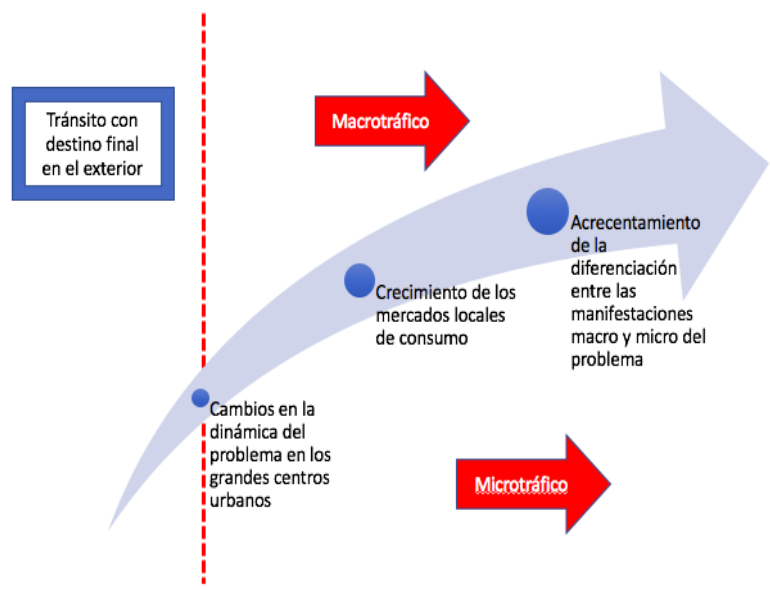

Estas transformaciones más recientes caracterizan una nueva manifestación del problema: el mesotráfico. ${ }^{44} \mathrm{El}$ mesotráfico es una manifestación más compleja a partir de la evolución de los mercados locales de consumo y las redes de abastecimiento destinadas a abastecer principalmente a los grandes conglomerados urbanos. Como afirma Sain:

Numerosas organizaciones han adquirido capacidades significativas de gerenciamiento del negocio narco en cuanto a ciertas dimensiones fundamentales del mismo: la adquisición de sustancias en países limítrofes y el traslado a las regiones de colocación del producto; la producción y estiramiento de las sustancias; el almacenamiento y la conformación de estructuras de venta al menudeo; la organización y puesta en funcionamiento de dispositivos de seguridad ante bandas rivales $\mathrm{u}$ organismos estatales; las negociaciones con la policía o funcionarios gubernamentales y la articulación de un esquema de sobornos y dádivas; la administración de los fondos generados por el emprendimiento

\footnotetext{
${ }^{44}$ Provincia de Salta, Secretaría de Programación para la Prevención de la Drogadicción y la Lucha contra el Narcotráfico y Agencia Antidrogas. Primer Estudio de Diagnóstico sobre Narcotráfico en la Provincia de Salta, octubre de 2011. Disponible en: http://www.soutozabaleta.com.ar/index.php/primer-estudio-de-diagnostico-sobre-narcotrafico-en-la-provincia-de-saltal
} 
mediante ocultamiento, inversiones o uso del mismo y el desarrollo de operaciones de lavado de dinero. Todo esto fue complejizando a las organizaciones narco pero nunca adoptaron una envergadura mayor que la local, es decir, con gravitación solo en una ciudad o en una sector de la misma. ${ }^{45}$

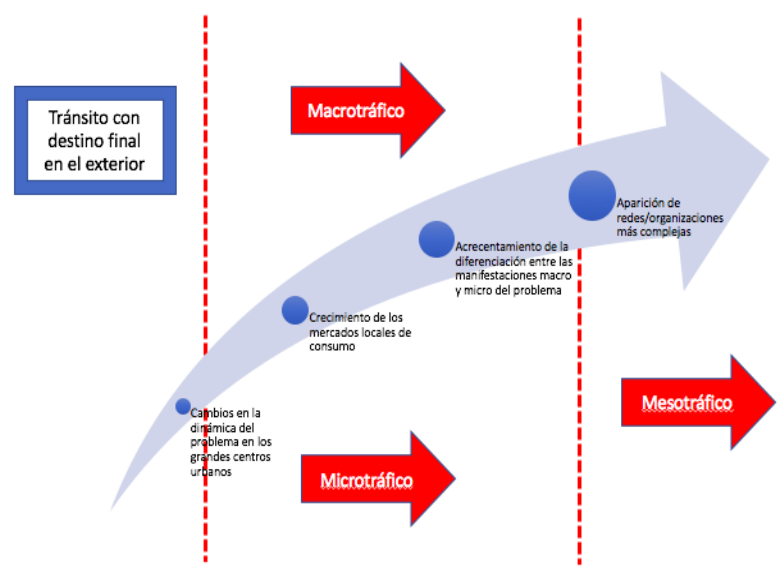

Estas transformaciones, que han pasado inadvertidas en el diseño e implementación de políticas de prevención y control del narcotráfico, son fundamentales a la hora de comprender el problema y delinear una estrategia para abordarlo. Como todo fenómeno que se manifiesta a partir de la emergencia y consolidación de mercados, el narcotráfico en Argentina se ha desplegado con características y dinámicas propias, en estrecha relación con las características de esos mercados, según la demanda, sean externos o domésticos. Pensar en políticas públicas sin diferenciar estas manifestaciones no puede conducir más que al fracaso.

\section{Una necesaria mirada a los mercados locales de consumo}

El crecimiento de los mercados locales de consumo que sostiene la diferenciación precedente entre las diversas manifestaciones del problema del narcotráfico en Argentina se verifica rápidamente al analizar la evolución de los

\footnotetext{
${ }^{45}$ Sain, Marcelo, "Entre mitos y fabulaciones políticas: el control del narcotráfico en Argentina (2003-2017)", Ponencia presentada en el XXXVI International Congress of the Latin American Studies Association, Barcelona, 23-26 de mayo, 2018.
} 
indicadores sobre la magnitud del consumo en el país. ${ }^{46}$ Según el informe elaborado por la Secretaría de Políticas Integrales sobre Drogas de la Nación Argentina, el consumo reciente de alguna droga ilícita pasó del 3.6\% en el año 2010 a 8.3\% en el 2017. Según este informe, hubo un gran aumento en las tasas de consumo de marihuana, cocaína, éxtasis y de alguna droga ilícita. ${ }^{47}$

En cuanto a los estupefacientes, el de mayor consumo, similarmente a lo que ocurre en todos los países de la región, es la marihuana. El período 2004-2017 muestra una tendencia creciente en todos los grupos de edad y en varones y mujeres. El informe hace hincapié en la población de entre 12 y 17 años; destaca que "el consumo de alguna droga ilícita en niños y adolescentes aumentó un 146\%". ${ }^{48}$ En 2010, uno de cada cien niños y adolescentes consumió marihuana en el último mes; la ratio para 2017 es tres de cada cien. El consumo de clorhidrato de cocaína en este grupo, por su parte, se triplicó en el período 2010-2017, mientras que el consumo de éxtasis incrementó 200\%. Estudios anteriores señalaban que los niveles de consumo estimados para pasta base-paco presentaban menos oscilaciones en relación con otras drogas y siempre en tasas inferiores a 0.6\%. Se advertía entonces que seguramente había sectores poblacionales en los cuales este consumo esté dominando el escenario, pero que las tasas que se presentaban eran promedios nacionales, lo que podía no dar cuenta real del problema. ${ }^{49}$

En efecto, a este crecimiento en la magnitud del consumo a nivel nacional debe agregarse la irrupción del problema del consumo de cocaínas fumables ("paco") que, aunque aparece como estadísticamente irrelevante en términos relativos, no puede dejar de considerarse como problemático. Como afirma

\footnotetext{
${ }^{46} \mathrm{Al}$ referirnos al mercado de consumo de sustancias en nuestro pais, y pese a no ser el objeto del presente trabajo, es oportuno recordar que la sustancia psicoactiva de mayor consumo es el alcohol. Los sucesivos estudios realizados muestran que la prevalencia es creciente, especialmente, en niños y adolescentes. El documento del Observatorio Argentino de Drogas (OAD) de la Secretaría de Políticas Integrales sobre Drogas de la república Argentina (Sedronar), basado en una encuesta realizada a estudiantes de enseñanza media de todo el país, señala que "en cuanto al consumo actual o del último mes [...] la mitad de los varones y las mujeres que cursan el nivel medio consumieron alcohol durante este periodo. La proporción aumenta con la edad, en especial a partir de los 15 años". A su vez, del Informe 2017 sobre consumo de sustancias psicoactivas elaborado por ese organismo sobre la población de 12 a 65 años, resulta que "de los niños y adolescentes que consumieron alcohol en el último mes, uno de cada dos lo hizo de forma abusiva". Sedronar, Análisis del Consumo de alcohol en población escolar. Sexta Encuesta Nacional a Estudiantes de Enseñanza Media Argentina, 2016. Disponible en: http://www.observatorio.gov.ar/media/k2/attachments/AnlisisZdelZConsumoZdeZAlcoholZenZPoblacinZEscolar.Z2016._1.pdf

47 Sedronar, Estudio Nacional en población de 12 a 65 años, sobre Consumo de Sustancias Psicoactivas. Argentina 2017. Disponible en: http://www.observatorio.gov.ar/media/k2/attachments/2017-10-05ZEncuestaZHogaresZconZcuestionario.pdf

${ }^{48}$ Idem, p. 5.

${ }^{49}$ Observatorio Argentino de Drogas, "Tendencia en el consumo de sustancias psicoactivas en Argentina, $2004-2010$. Población de 16 a 65 años", Argentina, Observatorio Argentino de Drogas, 2011.
} 
un estudio realizado por el Observatorio Interamericano de Drogas, esta irrupción estuvo acompañada por episodios de intoxicación en salas de emergencia, incremento de la demanda de tratamiento, problemas de inseguridad y vulnerabilidad y episodios de violencia y demanda de atención y ayuda por parte de familiares. Los estudios tradicionales en población general o en estudiantes secundarios no habían alertado sobre la gravedad de este patrón de consumo porque precisamente se encontraba focalizado en sectores sociales y territoriales específicos, tales como favelas, villas de emergencia y sectores de mayor pobreza en las grandes urbes de cada país. Como explican los autores del informe, fueron necesarias nuevas metodologías para conocer y estimar a la población con consumo de pasta base en las llamadas poblaciones ocultas o sectores de difícil acceso..$^{50}$

Esta tendencia al crecimiento de los mercados locales de consumo se ha visto acompañada, además, por un crecimiento en las percepciones vinculadas con la disponibilidad y comercialización ilícita de drogas. El informe del Observatorio de la Deuda Social Argentina, publicado en 2015, afirma lo siguiente:

A lo largo del período 2010-2014 tuvo lugar un incremento en la percepción sobre la existencia de venta de drogas en los barrios. Entre esos años el registro de venta de drogas en los barrios se incrementó un 50\%, llegando este reconocimiento al 45\% de los hogares urbanos. La evolución tuvo un incremento abrupto entre los años 2010 y 2011 para experimentar posteriormente un aumento constante. Entre los años 2010 y 2014, el incremento en el registro de venta de drogas tuvo lugar para todos los tipos de barrios. Sin embargo, este aumento no fue simétrico entre ellos. Mientras que para los barrios de nivel socio-económico medio alto el incremento fue cercano a un 30\%, para el resto el aumento se ubicó entre el 50 y el 60\% entre 2010-2014. ${ }^{51}$

Por otra parte, en el informe de 2016, el Observatorio señala:

En el período 2010-2015 se observa un importante incremento del registro de venta de drogas en el barrio. En otras palabras, aumenta de manera significativa la proporción de hogares que perciben de manera

\footnotetext{
50 Observatorio Interamericano de Drogas, "Consumo de drogas y vulnerabilidad social: Ias cocainas fumables", II Jornadas de Sociología de la Universidad Nacional de Cuyo, 2015.

${ }^{51}$ Observatorio de la Deuda Social Argentina, "Aumento del tráfico de drogas en los barrios, problemas de adicciones severas en las familias y poblaciones en riesgo", Barómetro del narcotráfico y las adicciones en Argentina, núm. 1. Disponible en: http://www.uca.edu.ar/uca/common/grupo68/files/2015-Obs-Narcotrafico-y-Adicciones-Boletin-Tematico-I.pdf
} 
directa o indirecta que en su barrio se venden drogas ilegales. A finales de 2015, casi 5 de cada 10 hogares identifican la venta o tráfico de drogas en su calle, manzana o vecindario. Los valores más altos en el registro de venta de drogas corresponden a las regiones urbanas de mayor concentración de población (el AMBa y la Región Pampeana), así como también al norte del país (NEA y NOA). Sin embargo, las regiones que registraron mayor crecimiento entre 2010-2015 fueron la Patagonia y el NEA, así como también el Conurbano bonaerense. ${ }^{52}$

\section{Ejes problemáticos en las políticas de prevención y control del narcotráfico en Argentina}

Frente a la evolución descripta en torno a los indicadores de oferta y demanda de estupefacientes, una serie de ejes problemáticos ha caracterizado la gestión de las políticas de prevención y control del narcotráfico en Argentina en los últimos años: a) una conceptualización del problema desde una retórica belicista con una consiguiente "tendencia militarizante"; b) la ausencia de un diagnóstico en el diseño e implementación de las políticas, con el agravante de la existencia de profundos errores de diagnóstico; c) una tendencia analíticamente limitada en el análisis de la efectividad de las políticas implementadas y una profunda indiferencia respecto de la consideración del impacto de esas políticas; $d$ ) una ausencia de planes y programas ajustados a la realidad local; e) una delegación política de la gestión a las instituciones policiales con altos niveles de autonomía y fragmentación policial en el abordaje del problema y complejas estrategias de vinculación con ciertos organismos extranjeros. Estos ejes, si bien no agotan el posible análisis de las políticas de prevención y control del narcotráfico en nuestro país, constituyen en conjunto importantes limitantes para un abordaje efectivo del problema que, como hemos visto, fue adquiriendo complejidad en los últimos 15 años.

a) La conceptualización del problema desde una retórica belicista y la "tendencia militarizante"

En el preámbulo del "Plan Argentina sin narcotráfico", lanzado el 30 de agosto de 2016, el Gobierno se comprometía no sólo a "dar la pelea sino también a

\footnotetext{
${ }^{52}$ Observatorio de la Deuda Social Argentina, "Barómetro del Narcotráfico y las Adicciones en la Argentina", Informe, núm. 3.
} 
ganarla". ${ }^{53}$ Esta retórica belicista y exitista frente al problema de las drogas en general y del narcotráfico en particular no es nueva: nos retrotrae a los discursos que tuvieron lugar en ocasión de la Sesión Especial de la Asamblea General de Naciones Unidas en 1998. Esta perspectiva contrasta con la postura de gran parte de la comunidad internacional, que está planteando un abandono de estas políticas en pos de un paradigma que integre como prioritaria a la salud pública y que atienda a una visión más amplia del problema.

Es importante destacar que la anterior administración, especialmente en los últimos años, compartía ciertos rasgos de esta visión sobre la forma de encarar el problema del narcotráfico. Aunque el entonces secretario de Seguridad afirmaba que "la guerra contra las drogas había fracasado", ${ }^{44}$ una serie de acciones tendientes a la militarización de la cuestión comenzaron a perfilarse en ese entonces. De hecho, como afirma Saín, “durante la última década, en la Argentina, se ha venido desarrollando un proceso de militarización lenta y atenuada del control del narcotráfico sin que haya mediado una reforma legal que la autorizara". ${ }^{55}$ De acuerdo con el autor, "la primera etapa de ese proceso de militarización se llevó a cabo durante la última administración presidencial de Cristina Fernández (2007-2011 y 2011-2015) y bajo la conducción del teniente general César Milani, jefe del Ejército Argentino”, quien “impulsó y desarrolló la intervención de esta fuerza en labores de patrullamiento y vigilancia en la frontera norte del país para conjurar el narcotráfico, pese a la prohibición legal existente al respecto". ${ }^{56}$

Siguiendo a Saín, una segunda etapa se inicia "con la llegada de Mauricio Macri (2015-2019) a la presidencia de la nación. A partir de entonces se habilitó la intervención de la Fuerza Aérea en la vigilancia aeroespacial del país y la eventual conjuración de vuelos irregulares en la jurisdicción nacional. También se llevaron a cabo iniciativas y alocuciones tendientes a habilitar el involucramiento militar en labores de seguridad interior". ${ }^{57}$ Aparece de hecho

\footnotetext{
53 "Argentina sin narcotráfico. El objetivo que nos une a todos", Gobierno de Argentina. Disponible en: https://www. argentina.gob.ar/seguridad/argentinasinnarcotrafico

${ }^{54}$ Véase "Berni: 'Detenemos delincuentes y los liberan el mismo día', Télam, 12 de marzo, 2014. Disponible en http:// www.telam.com.ar/notas/201403/55022-berni-detenemos-delincuentes-y-los-liberan-el-mismo-dia.html

${ }^{55}$ SaIn, Marcelo, "Fuerzas Armadas y narcotráfico: la «lenta» militarización del control del narcotráfico en Argentina (2011-2017)", Ponencia presentada en el XIII Congreso Nacional de Ciencia Política organizado por la Sociedad Argentina de Análisis Político, Buenos Aires, Argentina, 2-5 de agosto, 2017.

${ }^{56}$ Sain, Marcelo, "Fuerzas Armadas y narcotráfico: la «lenta» militarización del control del narcotráfico en Argentina (2011-2017)", Ponencia presentada en el XIII Congreso Nacional de Ciencia Política organizado por la Sociedad Argentina de Análisis Político, Buenos Aires, Argentina, 2-5 de agosto, 2017.

${ }^{57}$ Sain, Marcelo, "Fuerzas Armadas y narcotráfico: la «lenta» militarización del control del narcotráfico en Argentina (2011-2017)", Ponencia presentada en el XIII Congreso Nacional de Ciencia Politica organizado por la Sociedad
} 
una inquietante apelación a ampliar la participación de las fuerzas armadas en el abordaje del problema del narcotráfico. En palabras del presidente, "en esta nueva etapa que hemos iniciado nos propusimos alcanzar la pobreza cero, derrotar al narcotráfico y unir a los argentinos. En estas tres premisas las Fuerzas Armadas jugarán un rol preponderante y participativo". ${ }^{58}$ Para el presidente, las instituciones castrenses deben tener un rol destacado, tanto en la inserción de Argentina en el mundo como en el apoyo a la ciudadanía en situaciones de catástrofes climáticas y en el combate al narcotráfico. ${ }^{59}$

Lo problemático de este eje se vincula no sólo con cierto anacronismo en virtud de los actuales debates por los que atraviesa la comunidad internacional, sino principalmente con la ineficacia de este tipo de abordaje de acuerdo con las transformaciones que ha sufrido el problema del narcotráfico en Argentina y que hemos delineado precedentemente. Vemos entonces cómo este tipo de enfoques, además de innecesarios, resultan contraproducentes, especialmente frente a la emergencia de las manifestaciones micro y meso del problema del narcotráfico en Argentina.

\section{b) La ausencia de un diagnóstico y los "errores de diagnóstico"}

Así, en las políticas de prevención y control del narcotráfico, el tono belicista y la tendencia militarizante conviven con la ausencia de un diagnóstico riguroso y fundado, y con ciertos errores de diagnóstico. En efecto, las transformaciones por las que ha transitado el problema del narcotráfico en Argentina en la última década no parecen quedar reflejadas en el diagnóstico previo y la evaluación de las políticas que se vienen implementando para ninguna de las últimas gestiones de gobierno. Esas transformaciones dan lugar a distintas manifestaciones de tráfico (macro, meso y micro) con características distintivas en términos de las redes y organizaciones involucradas, cantidades comercializadas, calidad de las sustancias y la sofisticación logística que despliegan en su operatoria. Frente a ellas, las estrategias mayormente utilizadas parecen no establecer ningún tipo de diferenciación; además, muestran un anclaje en las tradicionales formas de

\footnotetext{
Argentina de Análisis Político, Buenos Aires, Argentina, 2-5 de agosto, 2017.

58 "Las Fuerzas Armadas jugarán un rol preponderante", Ámbito, 1 de agosto, 2016. Disponible en http://www.ambito.com/849408-las-fuerzas-armadas-jugaran-un-rol-preponderante

59 "Mauricio Macri elogió el rol castrense en la cena de camaradería de las Fuerzas Armadas", Télam, 13 de julio, 2017. Disponible en: http://www.telam.com.ar/notas/201707/195316-mauricio-macri-gobierno-nacional-cena-camaraderia-fuerzas-armadas-julio-martinez-oscar-aguad.html
} 
abordaje del problema y desatienden el impacto diferencial de cada una de las manifestaciones locales, que deberían obligar a tratamientos específicos.

A la ausencia de diagnóstico deben sumarse ciertos errores de diagnóstico. Las afirmaciones que muestran a Argentina como tercer proveedor mundial de cocaína $^{60}$ o como un país productor de estupefacientes ${ }^{61}$ caen en la trampa de no dimensionar la problemática de forma adecuada, a la luz de sus manifestaciones locales, y de agravar la importancia del problema. Asimismo, con ello se aleja el foco de las dinámicas concretas que implican su complejización y que demandan políticas de control de drogas diferenciadas y con una mirada más integral del problema.

Frente a la falta de un diagnóstico que permita elaborar una política de seguridad multiagencial para el abordaje del problema del narcotráfico, sólo aparecen en la retórica de los funcionarios discursos y acciones represivas y punitivas. En ese sentido se expresa Recasens I. Brunet: "a falta de verdaderas políticas de seguridad se llenará su carencia mediante la substitución por actividades de operadores, corporaciones u otros actores, que, de buena o mala fe, con mayor o menor pericia, trataran de colmar el espacio. Dichas actividades, por lo general, no coinciden con la definición propuesta por las políticas de seguridad, sino que responden a criterios e intereses corporativos, privados, sectoriales, o de otra índole, en función de lo que puedan, sepan o quieran hacer dichos operadores". ${ }^{62}$

${ }^{60}$ El primero de marzo de 2016, en su primer discurso de apertura de las sesiones del Honorable Congreso de la Nación, el presidente Macri se hacía eco de un dato publicado por la Oficina de Naciones Unidas contra la Droga y el Delito (ONUDD): "la Argentina es el tercer país proveedor mundial de cocaína". En efecto, esa información surgía de un análisis realizado por la ONUDD respecto a los "paises mencionados con más frecuencia en relación con distintos casos de incautación de drogas, por tipo de drogas (todos los modos de transporte)" para el período 2001-2012. Este caso es interesante porque resalta la gravedad de la ausencia de diagnósticos. En lo que refiere a la cocaína (incluyendo base, sales y crack), Argentina aparecia en el tercer lugar, luego de Brasil y Colombia. Cualquier lector no desprevenido hubiera advertido que no se trataba de nuestro pais caracterizado como proveedor mundial de cocaína sino, de acuerdo a la propia ONUDD, como el tercer pais en ser mencionado por otros paises como último lugar de paso de la sustancia en sus casos de incautación de cocaina. A raiz de las gestiones técnicas y diplomáticas realizadas oportunamente por el gobierno argentino, la ONUDD debió aclarar que la información vertida en el cuadro al que se hace referencia debía ser leída con cautela. "La onu corrigió un informe que señalaba a Argentina como tercer pais proveedor de cocaina", Diario Los Andes, 23 de septiembre, 2013. Disponible en: https://losandes.com.ar/ article/corrigio-informe-senalaba-argentina-como-tercer-proveedor-mundial-cocaina-740032

${ }^{61}$ Se trata este de otro de los errores de diagnóstico, ampliamente extendido, y se relaciona con la caracterización de nuestro país como de producción o fabricación de estupefacientes. La evolución de los centros de procesamiento ilícito de estupefacientes en Argentina muestra a las claras que no existe producción en el territorio nacional, que la fabricación ilícita es marginal en términos relativos y que las operatorias caracteristicas en este campo son las propias de la adulteración y el fraccionamiento de sustancias. Véase SedronaR, "Centros de procesamiento ilícito de estupefacientes en Argentina. Situación actual y tendencias 2000-2011". Disponible en: http://www.soutozabaleta. com.ar/index.php/centros-de-procesamiento-ilicito-de-estupefacientes-en-argentina/

${ }^{62}$ Recasens I Brunet, Amadeu, La seguridad y sus politicas, Barcelona, Atelier, 2007. 
La responsabilidad de los actores políticos en construir cambios significativos en las acciones de gobierno que permitan desplegar estrategias multiagenciales de prevención y control del narcotráfico, basadas en un diagnóstico de las condiciones y las causas que influyen en el problema del narcotráfico, es el principal desafío que debe encararse en pos de avanzar en abordajes más exitosos que los implementados hasta el momento.

\section{c) Los límites analiticos en la medición de la efectividad y la indiferencia de las politicas}

La información sobre incautaciones de estupefacientes es uno de los indicadores más utilizados para explicar la evolución del problema del narcotráfico. Su capacidad analítica, sin embargo, resulta limitada. Por ello, es incorrecto evaluar las políticas de prevención y control del narcotráfico de un país a partir de la lectura de ese indicador de manera aislada, máxime cuando el impacto de las incautaciones no produciría similares efectos respecto a las manifestaciones macro, micro o meso del problema.

Como señala Reuter, los esfuerzos por reducir la producción y el tráfico de drogas no han sido aún objeto de una evaluación sistemática, pero la mejor interpretación de la evidencia disponible es que han tenido un mínimo efecto en las cantidades producidas y traficadas. ${ }^{63}$ Pese a ello, y a las insuficiencias de la información de incautaciones, es esa la información que se utiliza para dar cuenta de la evolución del mercado de la comercialización ilícita de drogas en Argentina. Es decir, aun reconociendo la ambigüedad y las limitaciones del dato, persisten planteamientos en torno a la idea de que mayores incautaciones implican reducciones en la disponibilidad de estupefacientes en el mercado.

En esta línea, se supone que la elevación de riesgos con la potencialidad de desalentar la actividad delictiva y un impacto al alza en los precios de las sustancias terminan reduciendo el tamaño del mercado. Si bien existen pocas investigaciones empíricas que puedan dar cabal cuenta de estas correlaciones, lo existente descalifica absolutamente los presupuestos en los que descansa este tipo de análisis. Quizás una aplicación más dura de la ley pueda elevar los precios y para que reduzcan sustancialmente las cantidades consumidas. Sin embargo, el endurecimiento en la aplicación de la ley también genera más violencia en la competencia. Por ello, cualquier evaluación de la eficacia de la aplicación de

\footnotetext{
${ }^{63}$ Reuter, Peter, "Can Production and Trafficking of Illicit Drugs Be Reduced or Merely Shifted?", World Bank Policy Research Working Paper Series. Disponible en: https://ssrn.com/abstract=1111383
} 
la ley debe incluir el estudio de cómo la aplicación de la ley afecta la violencia, la enfermedad, las relaciones policía-comunidad, la corrupción. Si bien estas cuestiones son más difíciles de estudiar, son parte de un "juego limpio" en la agenda de investigación y los nuevos sistemas de información. ${ }^{64}$

La indiferencia respecto al impacto de las políticas implementadas también forma parte de este eje problemático. La aplicación del régimen penal de estupefacientes en Argentina, al igual que en la mayoría de los países del mundo, ha devenido en un sobresaliente incremento de la cantidad de detenidos en el transcurso de los últimos veinte años. Mientras que a principios de los noventa esa cifra no alcanzaba los 10000 detenidos por año, hacia la segunda década del nuevo milenio ya se aproximaba a los $60000 .{ }^{65}$ Este incremento se ha traducido claramente en un desborde de los sistemas policiales, judiciales y carcelarios, mientras la conflictividad asociada con la comercialización ilícita de estupefacientes no se ha visto reducida, siquiera contenida. De acuerdo con Corda, ${ }^{66}$ la población detenida en todo el país por infracción a la Ley de Estupefacientes se duplicó en la última década. En 2002 había en esas condiciones 3271 personas; en 2006 aumentó a 3981; en 2010, a 5846 y en 2013, a 6979 personas. Así, entre 2002 y 2013 el aumento fue de 113.35\%.

De acuerdo con un informe elaborado por la Procuraduría de Narcocriminalidad del Ministerio Público Fiscal, en el año 2015 46\% de las causas iniciadas en la Justicia Federal correspondían solamente a infracciones al régimen penal de estupefacientes. ${ }^{67}$ En este punto, tres circunstancias merecen destacarse. Primero, la mayoría de esas detenciones está asociada a la tenencia o comercialización ilícita de cannabis. ${ }^{68}$ Segundo, en la judicialización de estos casos se verifica una gran incidencia de delitos menores, tal como lo informa la Procunar, en su informe correspondiente al año $2015 .{ }^{69}$ En este contexto, re-

${ }^{64}$ Reuter, Peter, "The First Agenda For Drug Enforcement Research", Addiction, vol. 97, núm. 6. Disponible en: http:// onlinelibrary.wiley.com/doi/10.1046/j.1360-0443.2002.00070.x/full

${ }^{65}$ Véase SedRonar, Base de Datos de Procedimientos por Infracción a la Ley 23.737. 2012

${ }^{66}$ Corda, Alejandro, La estrategia fallida. Encarcelamientos por delitos relacionados con estupefacientes en Argentina, Argentina, Intercambios Asociación Civil - Universidad de Buenos Aires, 2016. Disponible en: http://www. drogasyderecho.org/publicaciones/pub-arg/Corda\%20-\%20La\%20estrategia\%20fallida.pdf

${ }^{67}$ Procunar, "Informe estadístico sobre narcocriminalidad, 2016". Disponible en: https://www.mpf.gob.ar/procunar-rii/files/2016/10/Informe-estad\%C3\%ADstico-sobre-Narcocriminalidad-2016.pdf

${ }^{68}$ En todo el período que va desde el año 1991 al año 2012,61\% de los procedimientos por infracción al régimen penal de estupefacientes se vinculaba sólo a incautaciones de ese tipo de sustancia. SEDRONAR. Base de Datos de Procedimientos por Infracción a la Ley 23.737. 2012

${ }^{69}$ De las causas iniciadas en la Justicia Federal, 52\% responde a las figuras de tenencia: 37\% a la tenencia para consumo personal y $15 \%$ a la tenencia simple. Como contracara, las figuras asociadas al tráfico ilícito de estupefacientes (incluyendo el contrabando) corresponden a $46 \%$ de las causas que se inician en el fuero federal. De acuerdo al Informe estadístico sobre narcocriminalidad de PROCUNAR 2016, en casi 5 de cada 10 causas se investigan los 
sulta significativa la importante cantidad de causas que se inician por tenencia para consumo personal.

La Procunar alerta desde 2013 que la mayoría de este último tipo de procesos no suelen proseguir su trámite, en concordancia con lo dispuesto en el fallo Arriola: esas causas suelen archivarse después de su ingreso al Poder Judicial. Por ello, "la inversión económica y la energía humana que se consume en todo el proceso que va desde la detención del infractor, la confección del sumario en papel, el ingreso al sistema judicial y el archivo del expediente, constituyen parámetros que deberían revisarse a la hora de evaluar en qué se gasta dinero y energía que luego faltan para investigaciones cualitativamente más importantes”.

En tercer lugar, es interesante señalar que, del total de causas iniciadas en la Justicia Federal en el año 2015, 62\% deriva de operaciones preventivas de las fuerzas de seguridad, esto es, no resultan de la inteligencia policial o de la investigación criminal, sino de tareas operativas de rutina, como los controles de ruta, vehiculares o fronterizos. Estas acciones punitivas y represivas que no están basadas en un diagnóstico sobre el problema, además de no ser efectivas, terminan siendo muy onerosas para los gobiernos y atentan contra la disponibilidad de los recursos necesarios para realizar estudios rigurosos o definir estrategias de prevención.

\section{d) Ausencia de planes y programas ajustados a la realidad local}

Tokatlian, respecto al Plan Argentina sin Narcotráfico, señala que algunos elementos merecen atención. Para el autor, este nuevo plan no parece "distanciarse mucho de lo planteado hace un cuarto de siglo. En efecto, en 1991, el Decreto Secreto 717 estableció el Plan Nacional contra el Tráfico Ilícito de Drogas a cargo de la Secretaría de Programación y Coordinación para la Prevención de la Drogadicción y la Lucha contra el Narcotráfico. En el preámbulo se afirmaba el carácter transnacional del fenómeno y el grave riesgo en que se encontraba el país.

La eliminación del narcotráfico era la meta principal; en pos de ella, se afirmaban como prioridades la coordinación federal, así como la cooperación internacional y la normalización de las estadísticas, la concreción de planes operativos terrestres, fluviales, aéreos y marítimos contra las drogas, y la colaboración entre todas las fuerzas de seguridad en el combate antinarcóticos. El 
"nuevo" plan de 2016 apunta a lo mismo y, como el de 1991, carece de precisión sobre los indicadores que servirán para evaluar la efectividad de la lucha que propone". Por otra parte, si se revisan los planes formulados durante la gestión anterior de gobierno, más allá de la retórica en los foros internacionales que muestra cambios a partir de 2012, se aprecia de igual manera que las planificaciones en el área parecen simplemente repetir el marco general de políticas que se establecen en las estrategias y planes de acción aprobados en el marco de la Comisión de Estupefacientes de Naciones Unidas o la Comisión Interamericana para el Control del Abuso de Drogas de la oEA.

En este contexto, y ante la ausencia de un diagnóstico sobre el problema que logre un entendimiento profundo de sus transformaciones en los últimos 15 años, ciertas medidas aparecen como problemáticas frente al actual estado de debate sobre políticas de drogas por el que atraviesa la comunidad internacional con respecto al énfasis punitivo. Es cierto que el decreto 1249/2016 declaró, a su vez, la "Emergencia Nacional en materia de Adicciones". A raíz de esa declaración, se dispuso una reasignación de partidas presupuestarias de $\$ 170000000.00$ adicionales para la Sedronar, organismo cuya competencia ha quedado reducida a la prevención y el tratamiento de las adicciones desde fines de 2013. En consecuencia, el presupuesto oficial de la Sedronar para el ejercicio 2017 ha sido de \$909 001688.00 , lo que implica un incremento real de $46.2 \%$ con respecto a $2016 .^{70}$ No obstante, el presupuesto del Ministerio de Seguridad para el año 2017 es de \$1 585110 193.00, que implica un aumento no sólo respecto del año anterior, sino 476\% de aumento en comparación con el presupuesto que tuvo la cartera en el período 2011-2015. ${ }^{71}$ Según Tokatlian, "resulta evidente que el conjunto de anuncios, pronunciamientos y medidas apunta en la dirección de 'argentinizar' la guerra contra las drogas en el contexto de las denominadas 'nuevas amenazas'. Para el autor, el Plan Argentina sin Narcotráfico, a cargo del Ministerio de Seguridad, implica que se ha elegido la opción más securitizada para el manejo del tema". ${ }^{72}$

Siguiendo a Corda, "resulta necesario repensar la actual estrategia desarrollada en torno al fenómeno de las drogas. Y para ello, dejar de pensarlo

\footnotetext{
70 "Algunas consideraciones sobre el presupuesto de la Sedronar", Política Argentina, 5 de diciembre, 2016. Disponible en http://www.politicargentina.com/notas/201612/18159-algunas-consideraciones-sobre-el-presupuestode-la-sedronar.html

71 "El presupuesto en seguridad de Macri creció 476\% en comparación con Cristina Kirchner", Infobae, 11 de agosto, 2017. Disponible en http://www.infobae.com/politica/2017/03/28/el-presupuesto-en-seguridad-de-macri-crecio-476-en-comparacion-con-cristina-kirchner/

72 "Juan Gabriel Tokatlian: 'Tenemos evidencia tangible de que la 'guerra contra las drogas' no sirve", La Nación, 30 de abril, 2017. Disponible en: http://www.utdt.edu/nota_prensa.php?id_nota_prensa=13432Etid_item_menu=442
} 
en términos de 'guerra' y entender que es un problema social y que algunas respuestas estatales pueden agravarlo". ${ }^{73}$ Así, coincidiendo con Tokatlian, "estamos en el peor de los mundos [...] no porque la Argentina se haya 'colombianizado' o 'mexicanizado', como suelen decir políticos y funcionarios agitando fantasmas sin fundamento fáctico que sirven como esgrima política, sino porque la Argentina carece de un diagnóstico integral y veraz sobre el narcotráfico y se empeña en persistir en políticas que ya han mostrado su rotundo fracaso en otros países del mundo". Para el autor, el entendimiento del problema por parte de la dirigencia "no sólo es exagerado. Es errado. En buena medida asumimos un conjunto de principios o parámetros para evaluar la situación de la Argentina que no tienen que ver efectivamente con lo que pasa en el país”, por lo que "estamos en mora de tener un buen diagnóstico: un diagnóstico integral, riguroso, basado en evidencia". ${ }^{74}$

No obstante, y en tanto determinadas problemáticas adquieren una formidable relevancia social, termina ocurriendo, como sostiene Curbet, que "las decisiones políticas están fuertemente condicionadas por la exigencia de adoptar medidas efectivas a corto plazo, que resulten populares y que no sean interpretadas por la opinión pública como muestras de debilidad o como un abandono a sus responsabilidades estatales. Así pues, las decisiones políticas en el ámbito del control del delito y la inseguridad tienden inevitablemente a buscar espectacularidad, cuando no el simple efectismo, y a evitar a cualquier precio que puedan ser acusadas, por la oposición política o los medios de comunicación, de alejarse del sentido común". ${ }^{75}$

\section{e) La autonomía policial y la cooperación con agencias extranjeras}

Los ejes problemáticos en las políticas de prevención y control del narcotráfico que venimos analizando resultan funcionales para el mantenimiento de un alto nivel de autonomía de las fuerzas policiales y de seguridad en el abordaje del problema del narcotráfico en Argentina. Como afirma Saín, “el sistema policial federal, compuesto por la Policía Federal Argentina, la Gendarmería Nacional, la Prefectura Naval Argentina y la Policía de Seguridad Aeroportuaria, se halla

\footnotetext{
${ }^{73}$ Corda, Alejandro, La estrategia fallida. Encarcelamientos por delitos relacionados con estupefacientes en Argentina, Argentina, Intercambios Asociación Civil - Universidad de Buenos Aires, 2016. Disponible en: http://www. drogasyderecho.org/publicaciones/pub-arg/Corda\%20-020La\%20estrategia\%20fallida.pdf

74 "Juan Gabriel Tokatlian: 'Tenemos evidencia tangible de que la 'guerra contra las drogas' no sirve", La Nación, 30 de abril, 2017. Disponible en: http://www.utdt.edu/nota_prensa.php?id_nota_prensa=13432\&tid_item_menu=442

${ }^{75}$ Curbet, Jaume, El rey desnudo: la gobernabilidad de la seguridad ciudadana, Barcelona, voc, 2009, p. 40.
} 
institucionalmente fragmentado en materia de control de la criminalidad organizada y el narcotráfico". Para el autor, "cada una de estas agencias cuenta con áreas especializadas en estas materias, pero son acotadas en su configuración organizativa y llevan a cabo las labores de inteligencia criminal y acciones conjurativas e investigativas de manera autogestionada y segmentada", por lo que "en concreto: cada fuerza o cuerpo policial, o cada sector o agrupamiento de una misma institución policial, formula e implementa sus propias acciones de control del narcotráfico". En este entendimiento, Binder coincide en que se trata de una continuidad en el abordaje del problema que ya había comenzado en la administración anterior, dando forma a un modelo de autonomía policial en el cual, además, las policías aparecen como desprofesionalizadas, con malos liderazgos y planes de formación. En suma, "no son controlables".

De acuerdo con Saín, "en la Argentina el modelo tradicional de seguridad pública presenta dos rasgos primordiales: en primer lugar, un desgobierno político provocado por la delegación sistemática de problemas de seguridad a la policía, lo que impulsa simultáneamente un proceso de policialización de la seguridad pública y de autonomización política de la policía; en segundo lugar, y como corolario del punto anterior, un autogobierno policial en términos doctrinales, orgánicos y funcionales. De esta manera se estructura un modelo de seguridad pública en el cual el sistema policial posee una modalidad de organización institucional centralizada y militarista". ${ }^{76}$

Sumado a los altos niveles de autonomía policial corresponde analizar, en particular, el rol de la DEA (Drug Enforcement Administration) en la gestión de las políticas de prevención y control del narcotráfico en Argentina. Tokatlian entiende que "con el gobierno de Cambiemos resurgió la panacea de apelar a la Administración de Control de Drogas de Estados Unidos (DEA) para hacer frente al narcotráfico en el país. El propósito, esta vez, es 'abrir una puerta que estaba cerrada', según palabras de la Ministra de Seguridad, Patricia Bullrich, durante su viaje a Washington en febrero de 2016”. Para el autor, la presidencia de Mauricio Macri encarna el resurgimiento de la quimera según la cual, con una mayor presencia de la DEA, la Argentina se enfrentará con mayor eficacia al narcotráfico. No obstante, debe decirse que a pesar de una cierta ambivalencia de la gestión anterior respecto a la DEA, en los últimos años hubo también un acercamiento con ese organismo.

\footnotetext{
${ }^{76}$ Sain, Marcelo, Seguridad, democracia y reforma del sistema policial en la Argentina, Buenos Aires, Fondo de Cultura Económica, 2002, p. 37.
} 
De acuerdo con Saín, la relación con este organismo norteamericano resulta problemática al resignar soberanía en el establecimiento de prioridades y el diseño de políticas públicas. Se pregunta entonces:

¿Teniendo en cuenta la capacidad real de control que tiene un país, a qué le damos prioridad? ¿A una red de narcotraficantes que está sacando 20 kilos de cocaína del país o a una red de narcotraficantes que trae un kilo de cocaína para ser comercializado aquí en una ciudad argentina? Para la DEA es prioritario lo primero, para nosotros debería ser prioritario lo segundo. Si yo estructuro mis intereses en torno de los de un organismo internacional compro sus prioridades que no siempre deben ser las mías, soberanamente hablando. No es necesario caerse de ningún mapa, a países como Argentina les sobra la capacidad institucional para encarar sus propias políticas criminales. Y la DEA tiene una capacidad enorme de establecimiento de la agenda de control del narcotráfico en Argentina. Lo ha tenido durante el kirchnerismo y lo tiene desde que Argentina se transformó en un país relevante como país de tránsito. No importa si en la última etapa hubo ministros y ministras con antipatía con la DEA, lo cierto es que por abajo siguieron operando".

\section{Reflexiones finales: la complejidad del problema y la necesidad de un diagnóstico}

En el presente trabajo mostramos la necesidad de una mejor comprensión de la magnitud y el funcionamiento del mercado ilícito de drogas en Argentina y de las particulares manifestaciones locales del problema del narcotráfico a la hora del diseño e implementación de políticas de prevención y control efectivas. Desde esta mirada, surge como prioritario complementar la información usualmente disponible en torno a la evolución de la oferta de drogas con otros indicadores que permitan evaluar de un modo más certero la evolución del narcotráfico en los últimos quince años, así como los resultados de las actuales estrategias de persecución policial y judicial.

Como hemos visto, si se analizan las cantidades de estupefacientes incautadas a lo largo de los años en complemento con otros indicadores vinculados con el crecimiento de los mercados locales de consumo, es posible observar una tendencia a un agravamiento y complejización del problema del narcotráfico a nivel nacional. Así, lo que se desprende de la tendencia creciente que marcan los indicadores sobre incautaciones sólo es comprensible si se analiza 
además la evolución de los indicadores de la magnitud del consumo a lo largo de esos años y el crecimiento de las percepciones vinculadas con la disponibilidad y comercialización ilícita de drogas, especialmente si se trabaja en un entendimiento más profundo de las transformaciones por las que ha atravesado el problema de narcotráfico a nivel nacional en los últimos quince años.

Frente a la evolución de los indicadores de oferta y demanda de estupefacientes, hemos advertido algunos ejes problemáticos de la gestión de las políticas de prevención y control del narcotráfico en Argentina en los últimos años: a) una conceptualización del problema desde una retórica belicista con una consiguiente "tendencia militarizante"; $b$ ) la ausencia de un diagnóstico en el diseño e implementación de las políticas, con el agravante de la existencia de profundos errores de diagnóstico; c) una tendencia analíticamente limitada en el análisis de la efectividad de las políticas implementadas y una profunda indiferencia respecto a la consideración del impacto de esas políticas; $d$ ) una ausencia de planes y programas ajustados a la realidad local; e) una delegación política de la gestión a las instituciones policiales con altos niveles de autonomía y fragmentación policial en el abordaje del problema y complejas estrategias de vinculación con ciertos organismos extranjeros.

Como afirma Caulkins, existe una necesidad de mejorar la efectividad de la aplicación de la ley, no sólo en términos de reducir la disponibilidad de drogas sino también en términos de reducir los daños asociados con los mercados de drogas, por lo que deberían desarrollarse nuevos indicadores que permitan evaluar la efectividad de las políticas de drogas de un modo integral. ${ }^{77}$ Se trata, sin dudas, de un inmenso desafío que requiere ante todo revisar los axiomas que han guiado históricamente la acción del Estado en la materia, y debería, en última instancia, conducir a cuestionar la eficiencia del modelo prohibicionista a la luz de sus efectos. Abandonar el énfasis en lo punitivo y centrarse en una mirada más orientada a la prevención requiere necesariamente tener como norte no sólo la reducción en la disponibilidad de drogas, sino los daños que los propios mercados ilícitos generan.

De acuerdo con Tokatlian, "en el marco general aún vigente de la guerra contra las drogas, algunas experiencias menos punitivas tienden a mostrar éxitos”. Estas iniciativas se ubican en una tendencia cada vez más evidente: modificar el paradigma prohibicionista y ensayar esquemas distintos que resulten más humanos, razonables y también efectivos. ${ }^{78}$ En suma, según Tokatlian, "el

\footnotetext{
77 Caulkins, Jonathan, "Measurement and analysis of drug problems and drug control effects", Measurement and analysis of Crime and Justice, vol. 4.

${ }^{78}$ TOKATLIÁn, JuAn, ¿Qué hacer con las drogas? Una mirada progresista sobre un tema habitualmente abordado desde
} 
mercado de las drogas está hoy regulado, pero son las mafias las que ejercen esa regulación". De acuerdo con el autor, "se requiere una mayor y mejor regulación estatal. Esto es: para regularizar el mercado de las drogas resulta fundamental que el Estado normativice y supervise mediante medidas específicas, reglas precisas y controles estrictos toda la cadena de ese negocio; ello, con el propósito de proteger a los ciudadanos, desmantelar la criminalidad asociada a la ilicitud de esa empresa y asegurar la confianza en las instituciones". ${ }^{79}$

En este sentido, las estrategias de los distintos gobiernos frente al narcotráfico en Argentina se han desentendido de las evidencias empíricas a nivel internacional que demuestran los resultados negativos del paradigma prohibicionista; a la vez, se han divorciado de un diagnóstico certero ajustado a las manifestaciones locales del problema. Como afirma un estudio del Programa de Naciones Unidas para el Desarrollo, las mediciones tradicionales del éxito de los esfuerzos para el control de drogas en términos de indicadores relacionados con la reducción de la oferta y la demanda (número de hectáreas de cultivos ilícitos erradicadas, cantidades de drogas incautadas y número de personas arrestadas, condenadas y encarceladas por violaciones a las leyes sobre drogas) revelan muy poco acerca del impacto del uso de las drogas o de las políticas en las vidas de las personas.

Según el informe, estas medidas no han considerado el impacto en los derechos humanos, en la inclusión social o en cualquier otro elemento del desarrollo humano sostenible: medir el éxito solamente en términos de arrestos e incautaciones puede crear incentivos perversos para las fuerzas del orden y pueden alentarles a involucrarse en situaciones de violencia u otros abusos para lograr estos objetivos. También puede conducir a que la policía se enfoque en perseguir a los infractores más débiles, como las personas que usan drogas o que comenten delitos menores relacionados con las drogas, ya que estos son fáciles de arrestar. De acuerdo con el informe, el desarrollo de un conjunto completo de métricas para medir toda la gama de asuntos de salud relacionados con las drogas, así como el impacto más amplio de las políticas de control de drogas en los derechos humanos, la seguridad y el desarrollo, sería una importante contribución a la discusión sobre las dimensiones del desarrollo de las políticas de control de drogas. ${ }^{80}$

\footnotetext{
el oportunismo politico y los intereses creados, Buenos Aires, Siglo XXI, 2017.

${ }^{79}$ TokAtLÁN, JuAn, ¿Qué hacer con las drogas? Una mirada progresista sobre un tema habitualmente abordado desde el oportunismo politico y los intereses creados, Buenos Aires, Siglo XXI, 2017.

80 Programa de Naciones Unidas para el Desarrollo, "Políticas de Control de Drogas y Desarrollo Humano", Programa de Naciones Unidas para el Desarrollo. Disponible en: http://www.undp.org/content/undp/es/home/librarypage/hivaids/addressing-the-development-dimensions-of-drug-policy.html
} 
El análisis de las transformaciones operadas en los últimos quince años en el mercado ilícito de drogas, así como los ejes problemáticos de las políticas implementadas sobre los que hemos reflexionado en estas páginas se constituyen así en un posible punto de partida para la revisión ineludible de las políticas de prevención y control del narcotráfico en Argentina que abran la puerta a estrategias centradas en lo preventivo y en la reducción de los daños que el propio mercado ilícito genera.

\section{Bibliografía}

"Algunas consideraciones sobre el presupuesto de la Sedronar", Politica Argentina, 5 de diciembre, 2016. Disponible en http://www.politicargentina.com/notas/201612/18159-algunas-consideraciones-sobre-el-presupuesto-de-la-sedronar.html

"Argentina sin narcotráfico. El objetivo que nos une a todos", Gobierno de Argentina. Disponible en: https://www.argentina.gob.ar/seguridad/argentinasinnarcotrafico

Baratta, Alessandro, Criminología y sistema penal (Compilación in memoriam), Buenos Aires, Editorial B de F, 2004.

BecKer, Howard, Outsiders. Hacia una sociología de la desviación, México, Siglo XXI, 2009.

Berger, Peter y Luckmann, Thomas, La construcción social de la realidad, Buenos Aires, Amorrortu, 1986.

"Berni: 'Detenemos delincuentes y los liberan el mismo día”, Télam, 12 de marzo, 2014. Disponible en http://www.telam.com.ar/notas/201403/55022-berni-detenemos-delincuentes-y-los-liberan-el-mismo-dia.html

BRYMAn, Alan, Social research methods, Oxford, Oxford University Press, 2004.

Caulkins, Jonathan, "Measurement and analysis of drug problems and drug control effects", Measurement and analysis of Crime and Justice, vol. 4.

CaUlkins, Jonathan, The distribution and consumption of illicit drugs: some mathematical models and their policy implications, MIT, 1990.

Corda, Alejandro, La estrategia fallida. Encarcelamientos por delitos relacionados con estupefacientes en Argentina, Argentina, Intercambios Asociación Civil - Universidad de Buenos Aires, 2016. Disponible en: http://www.drogasyderecho. org/publicaciones/pub-arg/Corda\%20-020La\%20estrategia\%20fallida.pdf

CuRBET, JaUme, El rey desnudo: la gobernabilidad de la seguridad ciudadana, Barcelona, Uoc, 2009.

Declaración del Director Ejecutivo del Programa de Naciones Unidas para la Fiscalización Internacional de Drogas (pnufid), Pino Arlacchi, en el Vigésimo Período Extraordinario de Sesiones de la Asamblea General de Naciones Unidas, A/S-20/P.V.1.

Declaración del Secretario General de Naciones Unidas en su Vigésimo Período Extraordinario de Sesiones, A/S-20/P.V.1, 1998. 
"El presupuesto en seguridad de Macri creció 476\% en comparación con Cristina Kirchner", Infobae, 11 de agosto, 2017. Disponible en http://www.infobae.com/politica/2017/03/28/el-presupuesto-en-seguridad-de-macri-crecio-476-en-comparacion-con-cristina-kirchner/

GARLAND, DAVID, La cultura del control. Crimen y orden social en la sociedad contemporánea, Madrid, Gedisa, 2001.

Intervención de Uruguay en la $43^{\circ}$ Asamblea General de la Organización de Estados Americanos, junio de 2013.

“Juan Gabriel Tokatlian: 'Tenemos evidencia tangible de que la 'guerra contra las drogas' no sirve”, La Nación, 30 de abril, 2017. Disponible en: http://www.utdt.edu/ nota_prensa.php?id_nota_prensa $=13432$ Ctid_item_menu $=442$

KILMER, Beau y HoOREns, STIJN, Understanding illicit drug markets, supply reduction efforts and drug related crime in the European Union, Comisión Europea, 2010.

"La onU corrigió un informe que señalaba a Argentina como tercer país proveedor de cocaina”, Diario Los Andes, 23 de septiembre, 2013. Disponible en: https://losandes.com.ar/article/corrigio-informe-senalaba-argentina-como-tercer-proveedor-mundial-cocaina-740032

“Las Fuerzas Armadas jugarán un rol preponderante”, Ámbito, 1 de agosto, 2016. Disponible en http://www.ambito.com/849408-las-fuerzas-armadas-jugaran-un-rolpreponderante

Marradi, Alberto, Archenti, Nélida, y Piovani, Juan, Metodología de las Ciencias Sociales, Buenos Aires, Emecé, 2007.

"Mauricio Macri elogió el rol castrense en la cena de camaradería de las Fuerzas Armadas", Télam, 13 de julio, 2017. Disponible en: http://www.telam.com.ar/notas/201707/195316-mauricio-macri-gobierno-nacional-cena-camaraderia-fuerzas-armadas-julio-martinez-oscar-aguad.html

Observatorio Argentino de Drogas, “Tendencia en el consumo de sustancias psicoactivas en Argentina, 2004-2010. Población de 16 a 65 años”, Argentina, Observatorio Argentino de Drogas, 2011.

Observatorio de la Deuda Social Argentina, “Aumento del tráfico de drogas en los barrios, problemas de adicciones severas en las familias y poblaciones en riesgo", Barómetro del narcotráfico y las adicciones en Argentina, núm. 1. Disponible en: http://www.uca.edu.ar/uca/common/grupo68/files/2015-Obs-Narcotrafico-y-Adicciones-Boletin-Tematico-I.pdf

Observatorio de la Deuda Social Argentina, "Barómetro del Narcotráfico y las Adicciones en la Argentina”, Informe, núm. 3.

Observatorio Interamericano de Drogas, "Consumo de drogas y vulnerabilidad social: las cocaínas fumables”, II Jornadas de Sociología de la Universidad Nacional de Cuyo, 2015.

Procunar, “Informe estadístico sobre narcocriminalidad, 2016”. Disponible en: https:// www.mpf.gob.ar/procunar-rii/files/2016/10/Informe-estad\%C3\%ADstico-sobre-Narcocriminalidad-2016.pdf 
Programa de Naciones Unidas Para el Desarrollo, "Políticas de Control de Drogas y Desarrollo Humano”, Programa de Naciones Unidas para el Desarrollo. Disponible en: http://www.undp.org/content/undp/es/home/librarypage/hiv-aids/addressing-the-development-dimensions-of-drug-policy.html

Recasens i Brunet, Amadeu, La seguridad y sus politicas, Barcelona, Atelier, 2007.

Reuter, Peter, "Can Production and Trafficking of Illicit Drugs Be Reduced or Merely Shifted?", World Bank Policy Research Working Paper Series. Disponible en: https://ssrn.com/abstract=1111383

Reuter, Peter, “The First Agenda For Drug Enforcement Research”, Addiction, vol. 97, núm. 6. Disponible en: http://onlinelibrary.wiley.com/doi/10.1046/j.1360-0443. 2002.00070.x/full

Reuter, Peter y Trautmann, Franz, A report on global illicit drug markets 1998-2007, European Commission, 2009.

SAin, Marcelo, "Entre mitos y fabulaciones políticas: el control del narcotráfico en Argentina (2003-2017)”, Ponencia presentada en el XXXVI International Congress of the Latin American Studies Association, Barcelona, 23-26 de mayo, 2018.

Sain, Marcelo, "Fuerzas Armadas y narcotráfico: la «lenta» militarización del control del narcotráfico en Argentina (2011-2017)”, Ponencia presentada en el XIII Congreso Nacional de Ciencia Política organizado por la Sociedad Argentina de Análisis Político, Buenos Aires, Argentina, 2-5 de agosto, 2017.

Sain, Marcelo, Seguridad, democracia y reforma del sistema policial en la Argentina, Buenos Aires, Fondo de Cultura Económica, 2002.

Sain, Marcelo y Rodríguez Games, Nicolás, Tendencias y Desafíos del Crimen Organizado en Latinoamérica, Buenos Aires, UMET, 2015.

Sedronar, Análisis del Consumo de alcohol en población escolar. Sexta Encuesta Nacional a Estudiantes de Enseñanza Media Argentina, 2016. Disponible en: http://www.observatorio.gov.ar/media/k2/attachments/AnlisisZdelZConsumoZdeZAlcoholZenZPoblacinZEscolar.Z2016._1.pdf

SEDRONAR, "Centros de procesamiento ilícito de estupefacientes en Argentina. Situación actual y tendencias 2000-2011”. Disponible en: http://www.soutozabaleta.com.ar/ index.php/centros-de-procesamiento-ilicito-de-estupefacientes-en-argentina/

SEDRonar, Estudio Nacional en población de 12 a 65 años, sobre Consumo de Sustancias Psicoactivas. Argentina 2017. Disponible en: http://www.observatorio.gov. ar/media/k2/attachments/2017-10-05ZEncuestaZHogaresZconZcuestionario.pdf

Souto Zabaleta, Mariana, Socialización, crisis de efectividad y persistencia en el régimen internacional de control de drogas, Buenos Aires, Editorial Arte \& Parte, 2017.

Sozzo, Máxımo, ¿Contando el delito? Análisis crítico y comparativo de las encuestas de victimización en Argentina, Argentina, Universidad Del Litoral, 2000.

TOKATLIÁn, JuAn, ¿Qué hacer con las drogas? Una mirada progresista sobre un tema habitualmente abordado desde el oportunismo politico y los intereses creados, Buenos Aires, Siglo XXI, 2017.

ZafFaroni, Eugenio, La cuestión criminal, Buenos Aires, Planeta, 2012. 